\title{
A model of friction for a pin-on-disc configuration with imposed pin rotation
}

\author{
A. Torres Pérez a,*, G. García-Atance Fatjó a, M. Hadfield ${ }^{\text {a }}$, S. Austen ${ }^{\text {b }}$ \\ a Sustainable Design Research Centre, Bournemouth University, Fern Barrow, Talbot Campus, Poole, Dorset BH12 5BB, UK \\ ${ }^{\mathrm{b}}$ Royal National Lifeboat Institution, Poole, UK
}

\section{A R T I C L E I N F O}

\section{Article history:}

Received 19 October 2010

Received in revised form 17 May 2011

Accepted 4 June 2011

Available online 7 July 2011

\section{Keywords:}

Pin-on-disc

Adhesive wear

Friction

Model

ECR

Conductance

\begin{abstract}
A B S T R A C T
A friction model is developed by considering the Coulomb friction model, a probabilistic approach of wear prediction, the kinematics of the pin-on-disc configuration and the elastic theory of bending. The model estimates the magnitude and direction of the frictional force, the pin torque, the probability of asperity contact and the real area of contact distinguishing between the part due to elastic and plastic asperity contacts respectively. Therefore, the proposed model is suitable for the prediction of adhesive wear. It can be applied to metal contacts for conductance characterisation through the plastically deformed asperities which is of great interest for electrical contact resistance studies.
\end{abstract}

(c) 2011 Elsevier Ltd. All rights reserved.

\section{Introduction}

The pin-on-disc configuration is a common test for the study of sliding wear. The pin on disc tester measures the friction and sliding wear properties of dry or lubricated surfaces of a variety of bulk materials and coatings [1]. For polymer testing, special pin on disc machines is used to report the wear rates produced using different pin-on-disc configurations [2]. Two basic pin-on-disc configurations are typically found depending of the loading of the pin along its major axis, which can be either in a direction normal (horizontal configuration) or parallel (vertical configuration) with the axis of rotation of the disc[2]. If the rotation of the pin is controlled by an actuator two new categories appear "horizontal configuration with imposed pin rotation" and a "vertical configuration with imposed pin rotation" respectively [3]. The interest of the former machines is that kinematically they are generalisation versions of the usual pin-on-disc machine where the pin is fixed. The kinematic study of this machine was reported in Ref. [4] and it is the fundamental pillar to devise the probabilistic friction and adhesive wear prediction models for the pin-ondisc apparatus.

In sliding contacts, adhesive wear mechanisms always occur [5]. Friction causes the asperities on one surface to become cold welded to the other surface. The volume of material transferred for adhesive wear is proportional to the real area of contact and the sliding distance. Several probabilistic models based on the Archard Adhesive Wear Law [6] for dry and lubricated contacts are found in the literature [7]. A complete review of the probabilistic approach for wear prediction in lubricated sliding contacts can be found in Ref. [8].

An initial study to model the friction is shown in Ref. [4]. Several improvements with respect to the former model are achieved by a frictional model based on the following assumptions:

- The pin is an elastic deformable body.

- The real area of contact changes with the ratio between the angular velocity of the pin and the angular velocity of the disc.

- The real area of contact depends on the compression and bending stresses acting on the pin.

\footnotetext{
* Corresponding author. Tel.: + 441202 965560; fax: + 441202965314.

E-mail address: atperez@bournemouth.ac.uk (A. Torres Pérez).
} 
- The interfacial shear strength, $\tau$, is independent of the local velocity [4].

- The interfacial shear strength is not a function of the magnitude of the local relative displacement [4].

A sequential methodology is followed which discusses the steps to be taken in order to develop the proposed model.

\section{Kinematic analysis of the pin-on-disc configuration with imposed rotation of the pin}

The kinematic analysis of the pin-on-disc setup with imposed rotation of the pin was developed in Ref. [4]. As a result, the pinon-disc configuration with imposed rotation of the pin is kinematically equivalent to the pin-on-plate configuration assuming a pin sliding along a straight line with velocity $\mathrm{V}=\omega_{\mathrm{d}} \mathrm{r}$ and simultaneously rotating about its centre, $\mathrm{O}_{\mathrm{p}}$ with angular velocity $\omega_{\mathrm{p}}$. The same conclusions can be drawn analysing the kinematics of the velocity vectors $\vec{u}, \vec{s}$ in one instant of time according to the system of reference $\mathrm{X}^{\prime} \mathrm{Y}^{\prime}$ of Fig. 1 .

The system of reference $X^{\prime} Y^{\prime}$ is fixed to the disc. The velocity field is analysed in the instant of time when the centre of the pin is aligned to the axis $Y^{\prime}$. XY is a local system of reference centred at $\left(X^{\prime}, Y^{\prime}\right)=(0, R)$ for convenience. The disc rotates with an angular velocity $\omega_{\mathrm{d}}$ and the pin rotates with an angular velocity $\omega_{\mathrm{p}}$ according to Fig. 1.

From Fig. 1, the field of velocities represented by the components $\vec{u}, \vec{s}$ of a point P within the pin for the instant of time when the centre of the pin is in $\left(\mathrm{X}^{\prime}, \mathrm{Y}^{\prime}\right)=(0, \mathrm{R})$ are shown in Eq. (1).

$$
\begin{aligned}
& u=\omega_{\mathrm{d}} \mathrm{R}+\left(\omega_{\mathrm{d}}-\omega_{\mathrm{p}}\right) \mathrm{y} \\
& s=\left(-\omega_{\mathrm{d}}+\omega_{\mathrm{p}}\right) \mathrm{x}
\end{aligned}
$$

Eq. (1) can be expressed in polar coordinates as shown in Eq. (2):

$$
\begin{aligned}
& \mathrm{x}=\mathrm{r} \cos (\theta) \\
& \mathrm{y}=\mathrm{r} \sin (\theta) \\
& u=\omega_{\mathrm{d}} \mathrm{R}+\left(\omega_{\mathrm{d}}-\omega_{\mathrm{p}}\right) \mathrm{r} \sin (\theta) \\
& \mathrm{s}=\left(-\omega_{\mathrm{d}}+\omega_{\mathrm{p}}\right) \mathrm{r} \cos (\theta)
\end{aligned}
$$

Where

$\mathrm{R} \quad$ Distance from the centre of the pin $\mathrm{O}_{\mathrm{p}}$ to the centre of the disc $\mathrm{O}_{\mathrm{d}}(\mathrm{m})$

$\mathrm{r} \quad$ Distance of a point $\mathrm{P}$ on the pin from its centre $\mathrm{O}_{\mathrm{p}}(\mathrm{m})$

$\omega_{\mathrm{d}} \quad$ Angular velocity of the disc about its centre, $\mathrm{O}_{\mathrm{d}}(\mathrm{rad} / \mathrm{s})$.

$\omega_{\mathrm{p}} \quad$ Angular velocity of the pin about its centre, $\mathrm{O}_{\mathrm{p}}(\mathrm{rad} / \mathrm{s})$.

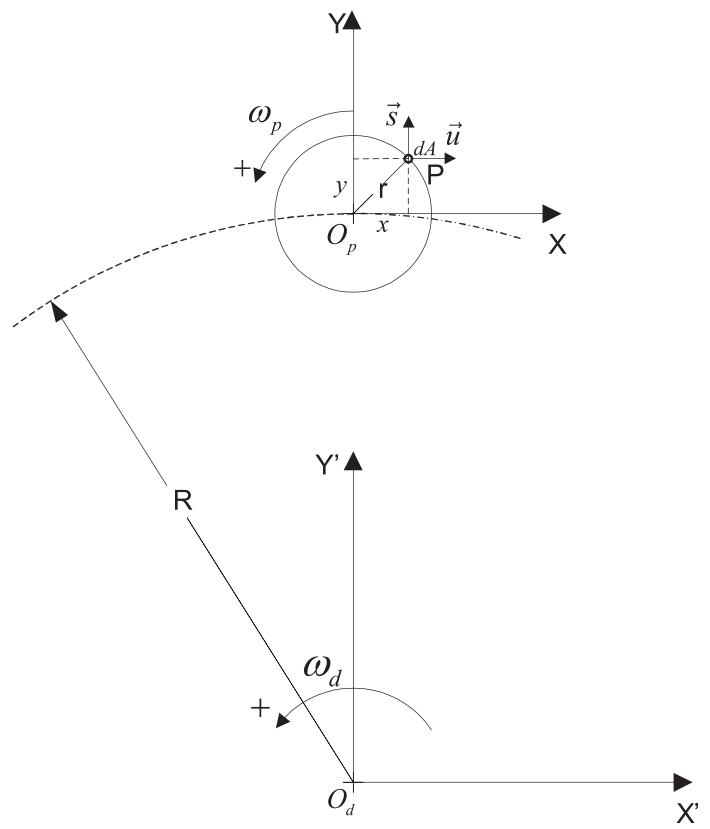

Fig. 1. Velocity vectors at point $\mathrm{P}$ within the pin with imposed rotation $\omega_{\mathrm{p}}$ in the pin-on-disc configuration. The system of reference $\left(\mathrm{X}^{\prime}, \mathrm{Y}^{\prime}\right)$ is fixed to the disc. 


\section{A probabilistic friction force model for pin-on-disc configuration}

The first step to devise the final model is to assume the following: the real contact area $\left(A_{r}\right)$ is proportional to the contact area (A), the real area of contact $\left(A_{r}\right)$ does not change with $\alpha$, and it is uniformly distributed within the contact area $(A)$. Under such conditions, the probability of asperity contact can be defined with a new parameter $p=A_{r} / A$. The real contact area and the probability of asperity contact are proportional to the local contact pressure. This is a result of the combination of Coulomb friction model and adhesive models as shown in Eq. (3).

$$
\mathrm{F}_{\mathrm{R}}=\mu N ; \mathrm{F}_{\mathrm{R}}=\mathrm{A}_{\mathrm{r}} \cdot \tau=\frac{\mathrm{A}_{\mathrm{r}}}{\mathrm{A}} \tau \cdot \mathrm{A} \Rightarrow \mathrm{p}=\mathrm{A}_{\mathrm{r}} / \mathrm{A}=\frac{\mu \cdot N}{\tau \cdot \mathrm{A}} \propto \frac{N}{\mathrm{~A}} \propto \sigma_{z}
$$

Where 'p' is the local relation between the real contact area and the contact area. This 'p' is a parameter that can be experimentally obtained.

According to the adhesion model of friction, each differential of the contact area (dA) contributes to the force acting on the pin by the contribution of the differential real contact area $(\mathrm{p} \cdot \mathrm{dA})$ and the interfacial shear stress, $(\tau)$. The sense of the friction force is opposite to the resultant force acting on the pin, where $\Psi$ is the angle of the resultant force acting on the pin [4]. The friction forces are shown in Eq. (4).

$$
\begin{aligned}
& \mathrm{F}_{\mathrm{R}_{\mathrm{x}}}=-\int_{A} \mathrm{p} \cdot \tau \cos (\psi) \mathrm{dA}=-\int_{0}^{\mathrm{r}_{\mathrm{p}}} \int_{0}^{2 \pi} \mathrm{p} \cdot \tau \cos (\psi) \mathrm{rd \theta dr} \\
& \mathrm{F}_{\mathrm{R}_{\mathrm{y}}}=-\int_{A} \mathrm{p} \cdot \tau \sin (\psi) \mathrm{dA}=-\int_{0}^{\mathrm{r}_{\mathrm{p}}} \int_{0}^{2 \pi} \mathrm{p} \cdot \tau \sin (\psi) \mathrm{r} d \theta d r \\
& \sin (\psi)=\frac{s}{\sqrt{\left(u^{2}+s^{2}\right)}}=\frac{\left(\omega_{\mathrm{p}}-\omega_{\mathrm{d}}\right) \mathrm{r} \cos (\theta)}{\sqrt{\left[\omega_{\mathrm{d}}^{2} \mathrm{R}^{2}+2 \mathrm{Rr} \omega_{\mathrm{d}}\left(\omega_{\mathrm{d}}-\omega_{\mathrm{p}}\right) \sin (\theta)+\left(\omega_{\mathrm{d}}-\omega_{\mathrm{p}}\right)^{2} \mathrm{r}^{2}\right]}} \\
& \cos (\psi)=\frac{u}{\sqrt{\left(u^{2}+s^{2}\right)}}=\frac{\omega_{\mathrm{d}} \mathrm{R}+\left(\omega_{\mathrm{d}}-\omega_{\mathrm{p}}\right) \mathrm{r} \sin (\theta)}{\sqrt{\left[\omega_{\mathrm{d}}^{2} \mathrm{R}^{2}+2 \mathrm{Rr} \omega_{\mathrm{d}}\left(\omega_{\mathrm{d}}-\omega_{\mathrm{p}}\right) \sin (\theta)+\left(\omega_{\mathrm{d}}-\omega_{\mathrm{p}}\right)^{2} \mathrm{r}^{2}\right]}}
\end{aligned}
$$

The previous expressions can be written in more elegant form using the parameter $\alpha=\omega_{\mathrm{p}} / \omega_{\mathrm{d}}$, Eq. (5).

$$
\begin{aligned}
& \mathrm{F}_{\mathrm{R}_{\mathrm{x}}}=-\int_{0}^{\mathrm{r}_{\mathrm{p}}} \int_{0}^{2 \pi} \mathrm{p} \cdot \tau \frac{[\mathrm{R}+(1-\alpha) \mathrm{r} \sin (\theta)] \mathrm{r}}{\sqrt{\left[\mathrm{R}^{2}+2 \mathrm{Rr}(1-\alpha) \sin (\theta)+(1-\alpha)^{2} \mathrm{r}^{2}\right]}} d r d \theta \\
& \mathrm{F}_{\mathrm{R}_{\mathrm{y}}}=-\int_{0}^{\mathrm{r}_{\mathrm{p}}} \int_{0}^{2 \pi} \mathrm{p} \cdot \tau \frac{(\alpha-1) \mathrm{r}^{2} \cos (\theta)}{\sqrt{\left[\mathrm{R}^{2}+2 \mathrm{Rr}(1-\alpha) \sin (\theta)+(1-\alpha)^{2} \mathrm{r}^{2}\right]}} d r d \theta
\end{aligned}
$$

The differential friction force which contributes to the differential friction torque is shown in Eq. (6):

$$
\mathrm{d} \overrightarrow{\mathrm{F}_{\mathrm{R}}}=\mathrm{dF}_{\mathrm{Rx}} \hat{x}+\mathrm{dF}_{\mathrm{Ry}} \hat{y}
$$

The differential torque is shown in Eq. (7).

$$
\begin{aligned}
& \mathrm{d} \overrightarrow{T_{\mathrm{F}}}=\vec{r} \times \mathrm{d} \vec{F}_{\mathrm{R}} \\
& \mathrm{d} \overrightarrow{T_{\mathrm{F}}}=\mathrm{r}\left(-\mathrm{dF}_{\mathrm{Rx}} \sin (\theta)+\mathrm{dF}_{\mathrm{Ry}} \cos (\theta)\right) \hat{z}
\end{aligned}
$$

The friction torque is shown in Eq. (8).

$$
\begin{aligned}
\mathrm{T}_{\mathrm{F}}= & \int_{0}^{\mathrm{r}} \int_{0}^{\mathrm{r}} \mathrm{p} \cdot \tau \frac{[\mathrm{R}+(1-\alpha) \mathrm{r} \sin (\theta)] \mathrm{r}^{2} \sin (\theta)}{\sqrt{\left[\mathrm{R}^{2}+2 \mathrm{Rr}(1-\alpha) \sin (\theta)+(1-\alpha)^{2} \mathrm{r}^{2}\right]}} d r d \theta \ldots \\
& -\int_{0}^{\mathrm{r}_{\mathrm{p}} 2 \pi} \int_{0}^{\mathrm{p}} \mathrm{p} \cdot \tau \frac{(\alpha-1) \mathrm{r}^{3} \cos ^{2}(\theta)}{\sqrt{\left[\mathrm{R}^{2}+2 \mathrm{Rr}(1-\alpha) \sin (\theta)+(1-\alpha)^{2} \mathrm{r}^{2}\right]}} d r d \theta
\end{aligned}
$$

Assuming a uniform distribution of the real contact area, the $y$-component of the frictional force is 0 . This conclusion can be drawn visualising that the sum of all velocities along ' $y$ ' direction is 0 . This is because the field of velocities along ' $y$ ' is an odd function in respect to the ' $x$ ' component which fulfils Eq. (9).

$$
s(\mathrm{X}, \mathrm{y})=-s(-\mathrm{x}, \mathrm{y})
$$

As a result, the ' $y$ ' component of the force acting on the pin is 0 according to this model. 


\section{Normalised results of the preliminary probabilistic friction model}

The integrals of Eqs. (4) and (8) are graphically determined for a wide range of input conditions using a suitable normalisation criterion. This normalisation criterion consists on dividing the Eqs. (4) and (8) by the pin area multiplied by the probability of asperity contact $(\mathrm{p})$ and by the interfacial shear stress $(\tau)$. Results are shown in Figs. 2-5 for a distance R from the centre of the disc to the centre of the pin of $25 \mathrm{~mm}$ and positive values of $\alpha$. Results for negative values of $\alpha$ are shown in Figs. 6-9.

When $\alpha$ is positive, the disc and the pin angular velocities have the same sense otherwise when $\alpha$ is negative, the angular velocities of the disc have opposite senses.

When $\alpha>0$ :

- $\mathrm{F}_{\mathrm{X}}$ is proportional to the contact area of the pin

- $\mathrm{F}_{\mathrm{x}}$ tends to be maximum when $\alpha<1$ or $\left|\omega_{\mathrm{d}}\right|>>\left|\omega_{\mathrm{p}}\right|$

- $\mathrm{F}_{\mathrm{x}}$ tends to be 0 when $\left|\omega_{\mathrm{p}}\right|>>\left|\omega_{\mathrm{d}}\right|$

When $\alpha>0$ :

- The frictional torque is 0 for $\alpha=1$ (The pin does not rotate in the pin on plate equivalent model)

- Frictional torque is negative for $\alpha<1$

- Frictional torque is positive for $\alpha>1$

- The frictional torque $\mathrm{T}$ is proportional to the pin radius.

When $\alpha<0$ :

- $\mathrm{F}_{\mathrm{x}}$ is proportional to the contact area of the pin

- $\mathrm{F}_{\mathrm{x}}$ tends to be maximum when $\left|\omega_{\mathrm{d}}\right|>>\left|\omega_{\mathrm{p}}\right|$

- $\mathrm{F}_{\mathrm{x}}$ tends to be 0 when $\left|\omega_{\mathrm{p}}\right|>>\left|\omega_{\mathrm{d}}\right|$

When $\alpha<0$ :

- The sense of the frictional torque $\mathrm{T}_{\mathrm{F}}$ does not change for all values of $\alpha$.

- The frictional torque is maximum if $\left|\omega_{\mathrm{p}}\right|>>\left|\omega_{\mathrm{d}}\right|$

- The frictional torque $\mathrm{T}_{\mathrm{F}}$ is proportional to the pin radius.

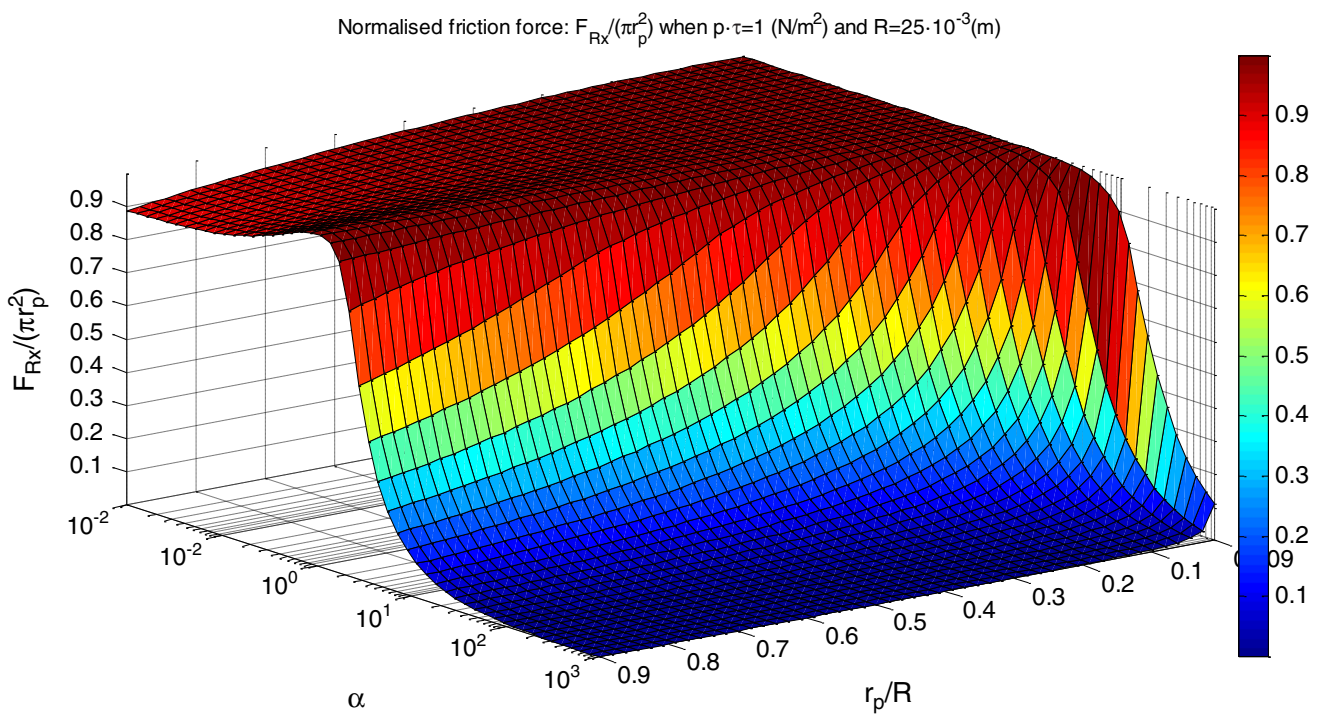

Fig. 2. Normalised $\mathrm{x}$-component of the friction force (3D). $\alpha \epsilon\left[10^{-2}, 10^{3}\right], \mathrm{r}_{\mathrm{p}} / \mathrm{R} \in[0.009,0.9]$. 


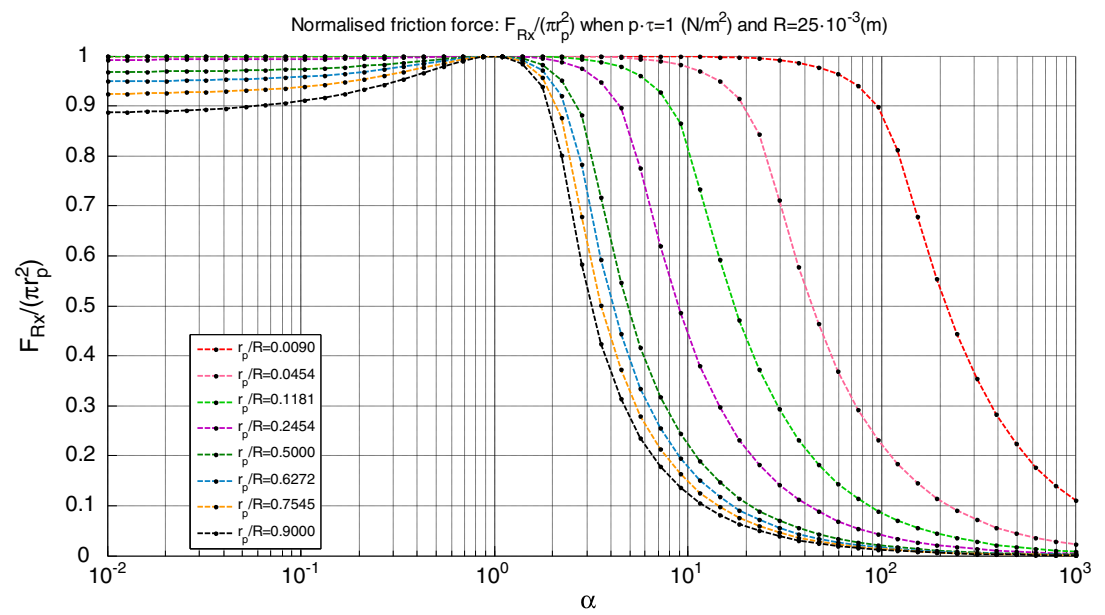

Fig. 3. Normalised $\mathrm{x}$-component of the friction force (2D). $\alpha \in\left[10^{-2}, 10^{3}\right], \mathrm{r}_{\mathrm{p}} / \mathrm{R} \in[0.009,0.9]$.

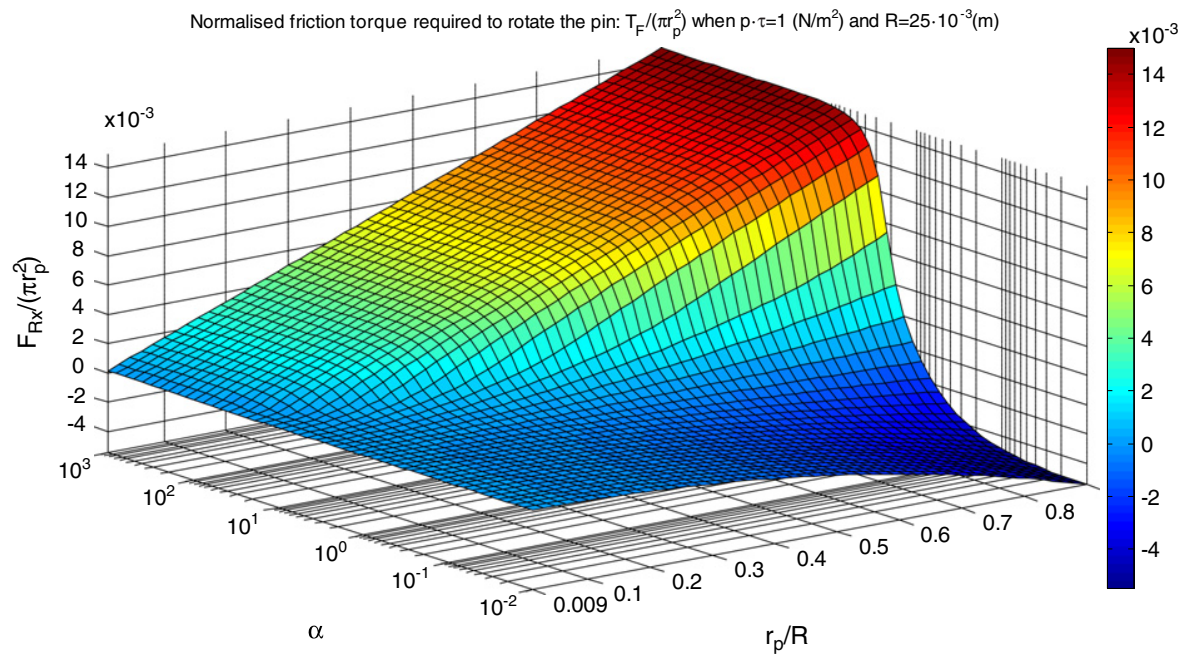

Fig. 4. Normalised friction torque (3D). $\alpha \epsilon\left[10^{-2}, 10^{3}\right], \mathrm{r}_{\mathrm{p}} / \mathrm{R} \in[0.009,0.9]$.

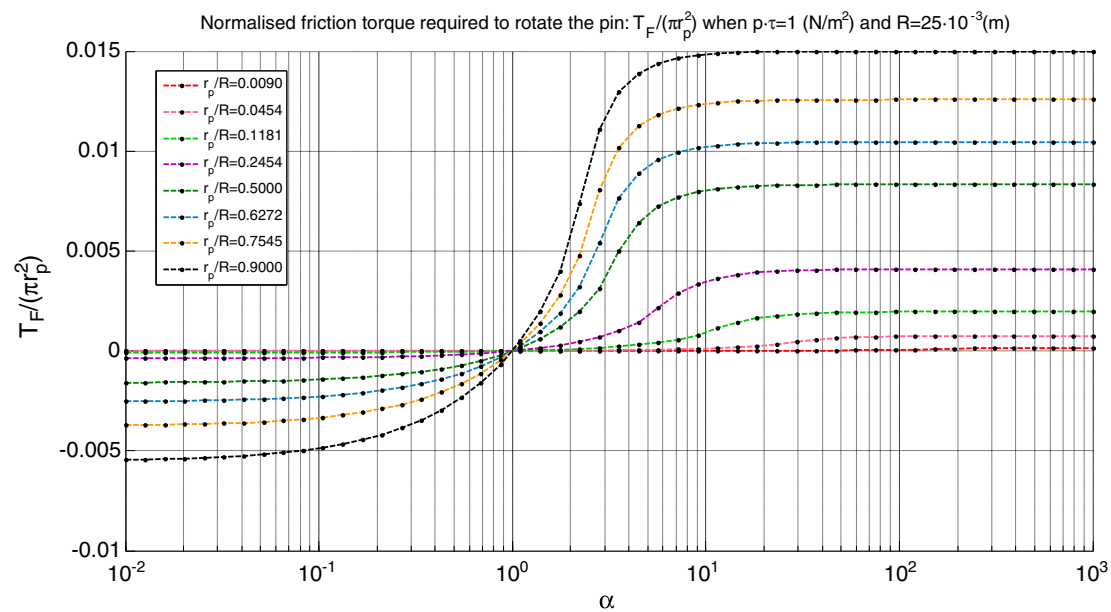

Fig. 5. Normalised friction torque (2D). $\alpha \epsilon\left[10^{-2}, 10^{3}\right], \mathrm{r}_{\mathrm{p}} / \mathrm{R} \in[0.009,0.9]$. 


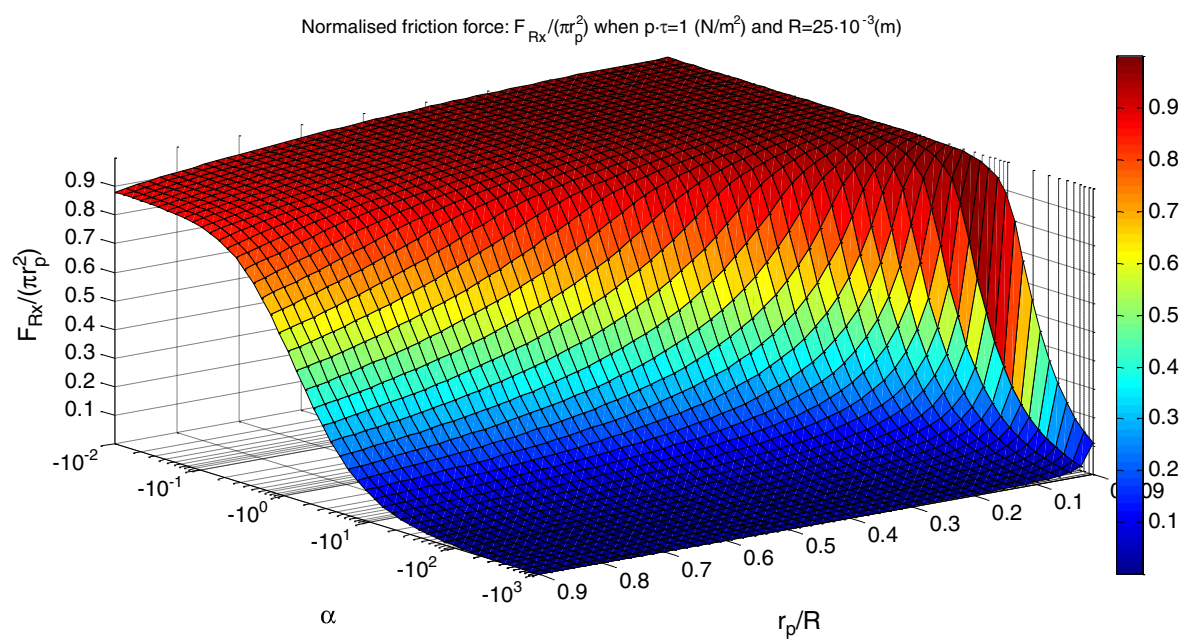

Fig. 6. Normalised $\mathrm{x}$-component of the friction force (3D). $\alpha \in\left[-10^{3},-10^{-2}\right], \mathrm{r}_{\mathrm{p}} / \mathrm{R} \in[0.009,0.9]$.

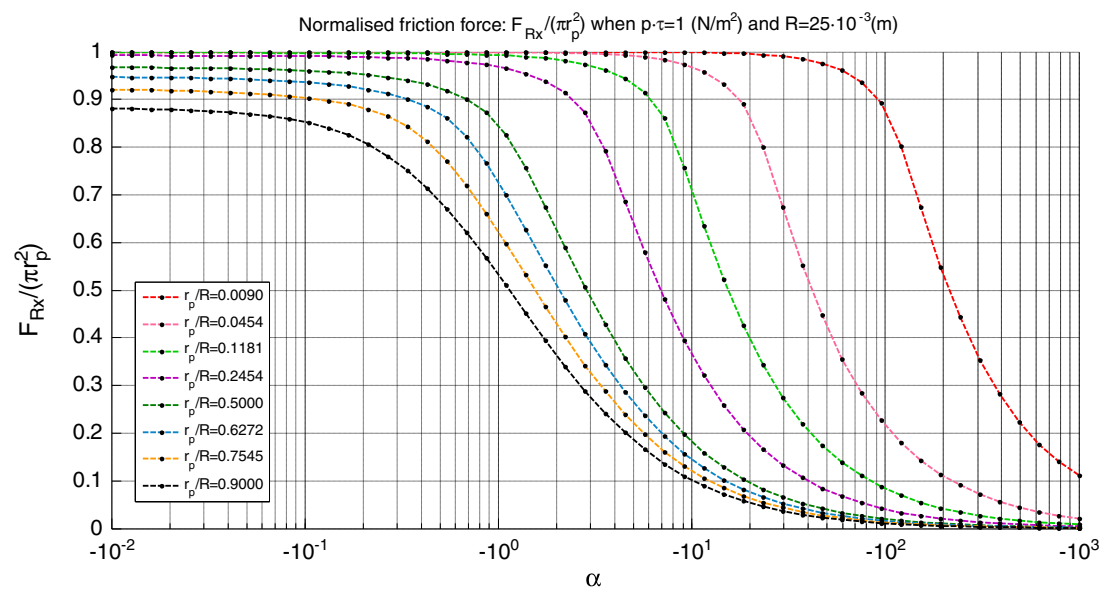

Fig. 7. Normalised $\mathrm{x}$-component of the friction force (2D). $\alpha \in\left[-10^{3},-10^{-2}\right], \mathrm{r}_{\mathrm{p}} / \mathrm{R} \epsilon[0.009,0.9]$.

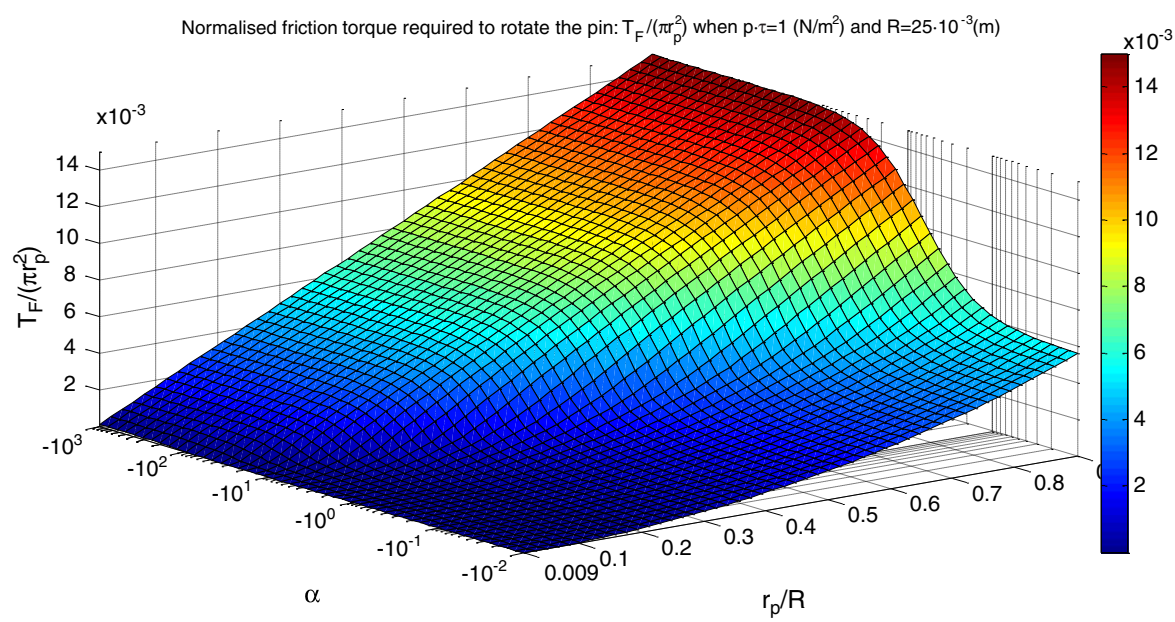

Fig. 8. Normalised friction torque (3D). $\alpha \epsilon\left[-10^{3},-10^{-2}\right], \mathrm{r}_{\mathrm{p}} / \mathrm{R} \in[0.009,0.9]$. 


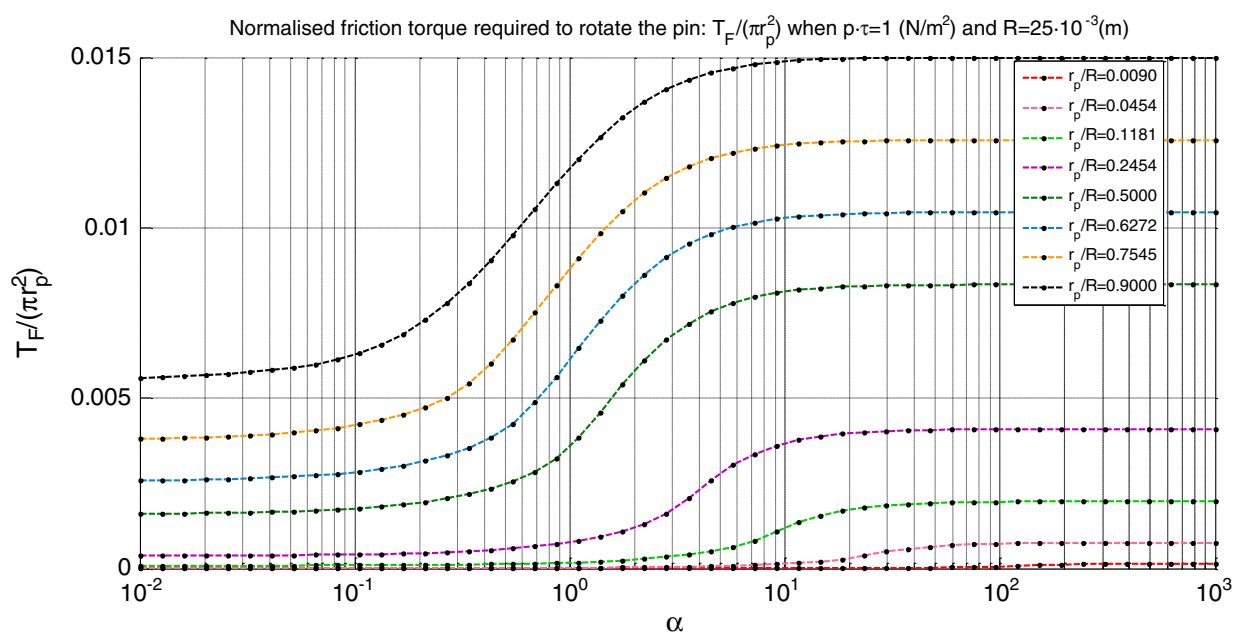

Fig. 9. Normalised friction torque (2D). $\alpha \epsilon\left[-10^{3},-10^{-2}\right], \mathrm{r}_{\mathrm{p}} / \mathrm{R} \in[0.009,0.9]$.

\section{Validation of the preliminary model with experimental data}

The experimental data is obtained from Ref. [4] and it is curve fitted using different types of regression (Figs. 10-12). Although $\phi$ is reported in Ref. [4] as inverse proportional to $\alpha$, the experimental data must be directly proportional to $\alpha$ to match the model tendencies according to Figs. 2-9. The experimental points and the types of regression used in Matlab are represented in Table 1.

Using the experimental data provided in Ref. [4], the best value of $\mathrm{p}$ according to the $\mathrm{x}$ component of the frictional can be obtained optimising the best value in least mean squares sense for the whole range of $\phi$. The model predictions are shown in Figs. 13,14 for a pin of $8 \mathrm{~mm}$ of diameter and positive values of $\alpha$ and $\phi$. The probabilities in such cases are shown in Table 2 . The model predictions are shown in Figs. 15,16 for a pin of $8 \mathrm{~mm}$ of diameter and negative values of $\alpha$ and $\phi$. The probabilities in such cases are shown in Table 3.

The friction torque predictions for positive and negative $\alpha$ are two orders of magnitude larger than the one reported in Ref. [4], but the scale of predictions is within the expected range according to the values of $F_{x}$ and a pin radius of 4 mm. The torque tendencies are not exactly the same as the experimental ones.

The next step is the assumption of a real area of contact uniform distributed within the contact area that can vary with the ratio of the angular velocity of the pin and the angular velocity of the disc $(\alpha)$. This assumption is reasonable as the coefficient of friction could change with the relative velocities within the contacting surfaces [11]. Therefore, the probability of asperity contact (p) is expressed as a function of $(\alpha)$.

The values of $\mathrm{p}$ can be obtained using the experimental ' $\mathrm{x}$ ' component of the total frictional force. The model predictions for the ' $y$ ' component are still null, so the experimental values cannot be used to determine p. According to this model, the real area of contact and the contact pressure change with $\alpha$. The proposed model has the limitation of a real area of contact totally plastic or

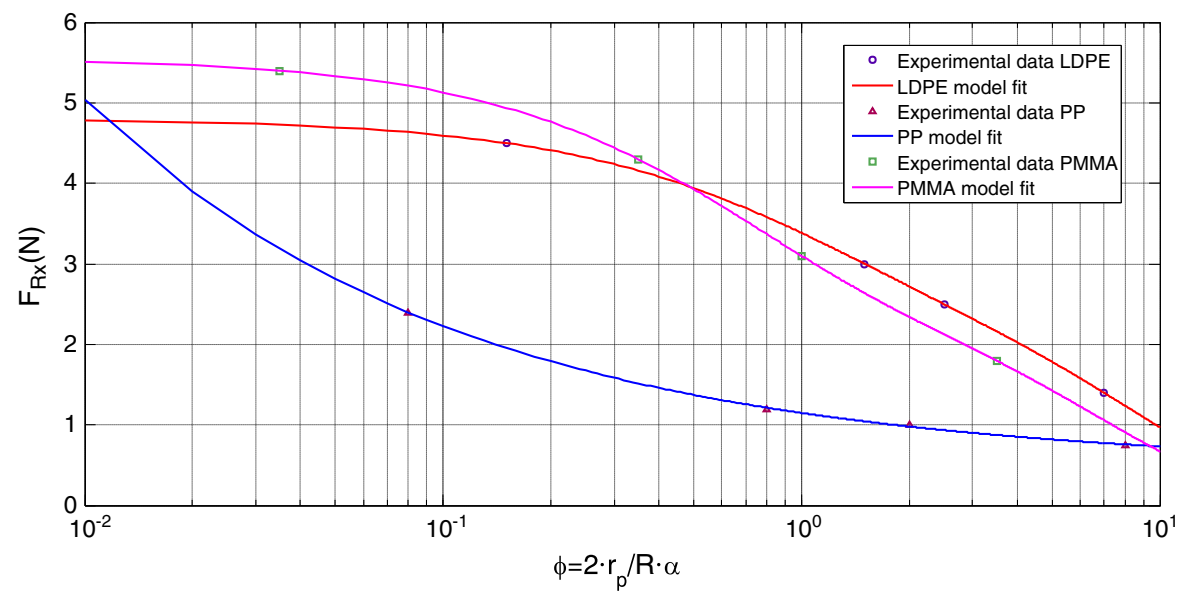

Fig. 10. Friction force $F_{R x}$. 


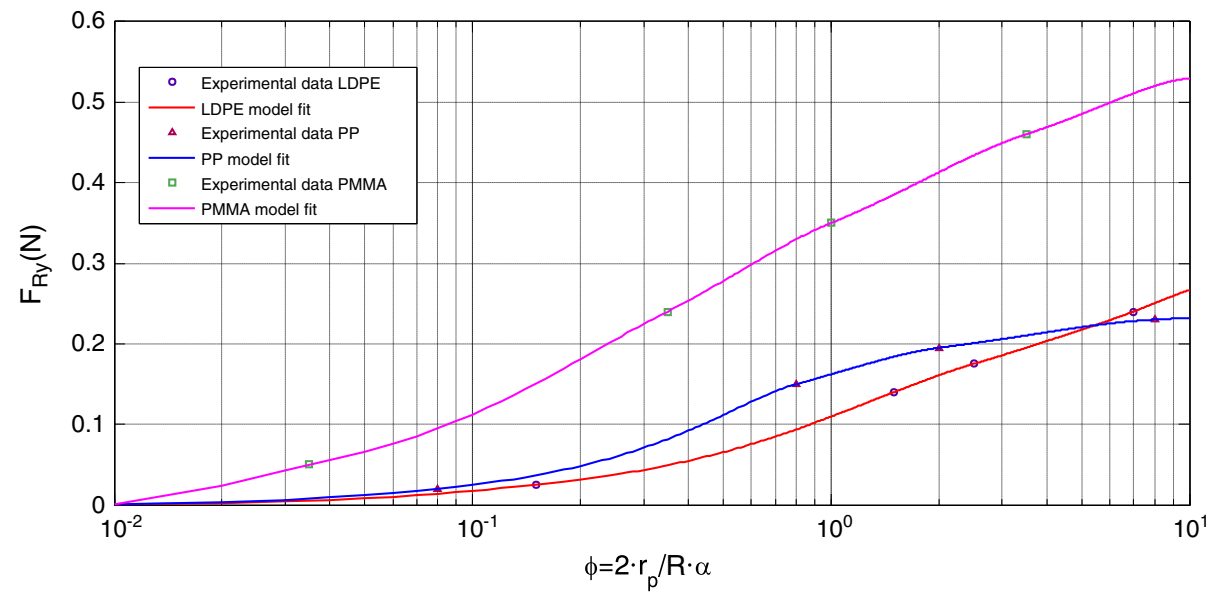

Fig. 11. Friction force $F_{R y}$.

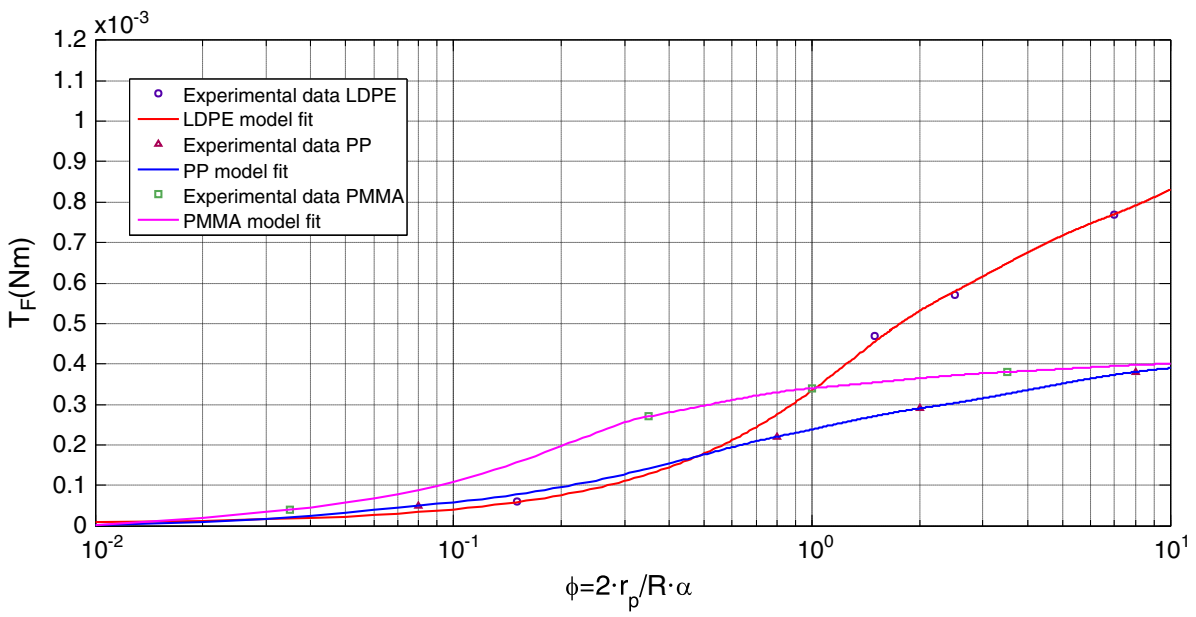

Fig. 12. Pin friction torque $T_{F}$.

Table 1

Experimental data obtained from [4].

Experimental conditions

$\mathrm{F}_{\mathrm{Rx}}(\mathrm{N})$

$\mathrm{F}_{\mathrm{Ry}}(\mathrm{N})$

$\mathrm{T}_{\mathrm{F}}(\mathrm{Nm})$

Experimental conditions

$\mathrm{F}_{\mathrm{Rx}}(\mathrm{N})$

$\mathrm{F}_{\mathrm{Ry}}(\mathrm{N})$

$\mathrm{T}_{\mathrm{F}}(\mathrm{Nm})$

Experimental conditions

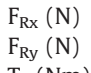

$\mathrm{F}_{\mathrm{Ry}}(\mathrm{N})$

$\mathrm{T}_{\mathrm{F}}(\mathrm{Nm})$
PP (polypropylene)

Normal load $=10 \mathrm{~N}, \mathrm{R}=25 \cdot 10^{-3}(\mathrm{~m}), \tau=13 \cdot 10^{6}\left(\mathrm{~N} / \mathrm{m}^{2}\right)$

$\phi_{1}=0.08 \quad \phi_{2}=0.8 \quad \phi_{3}=2$

$\begin{array}{llll}2.4 & 1.2 & 1 & 0.75\end{array}$

$\begin{array}{lll}0.02 & 0.15 & 0.20\end{array}$

$5 \cdot 10^{-5} \quad 22 \cdot 10^{-5} \quad 29 \cdot 10^{-5}$

0.75

$38 \cdot 10^{-5}$

'power2'

'pchipinterp'

LDPE (low density polyethylene)

Normal load $=10 \mathrm{~N}, \mathrm{R}=25 \cdot 10^{-3}(\mathrm{~m}), \tau=8.1 \cdot 10^{6}\left(\mathrm{~N} / \mathrm{m}^{2}\right)$

$\begin{array}{lllll}\phi_{1}=0.15 & \phi_{2}=1.5 & \phi_{3}=2.5 & \phi_{4}=7 & \text { Type of regression } \\ 4.5 & 3 & 2.5 & 1.4 & \text { 'exp2' } \\ 0.03 & 0.14 & 0.18 & 0.24 & \text { 'pchipinterp' } \\ 6 \cdot 10^{-5} & 47 \cdot 10^{-5} & 57 \cdot 10^{-5} & 77 \cdot 10^{-5} & \text { 'smoothingspline' }\end{array}$

PMMA (polymethyl metacrylate)

Normal load $=10 \mathrm{~N}, \mathrm{R}=25 \cdot 10^{-3}(\mathrm{~m}), \tau=1.95 \cdot 10^{8}\left(\mathrm{~N} / \mathrm{m}^{2}\right)$

\begin{tabular}{lllll}
$\phi_{1}=0.035$ & $\phi_{2}=0.35$ & $\phi_{3}=1$ & $\phi_{4}=3.5$ & Type of regression \\
5.4 & 4.3 & 3.1 & 1.8 & 'exp2' \\
0.05 & 0.24 & 0.35 & 0.46 & 'pchipinterp' \\
$4 \cdot 10^{-5}$ & $27 \cdot 10^{-5}$ & $34 \cdot 10^{-5}$ & $38 \cdot 10^{-5}$ & 'pchipinterp' \\
\hline
\end{tabular}




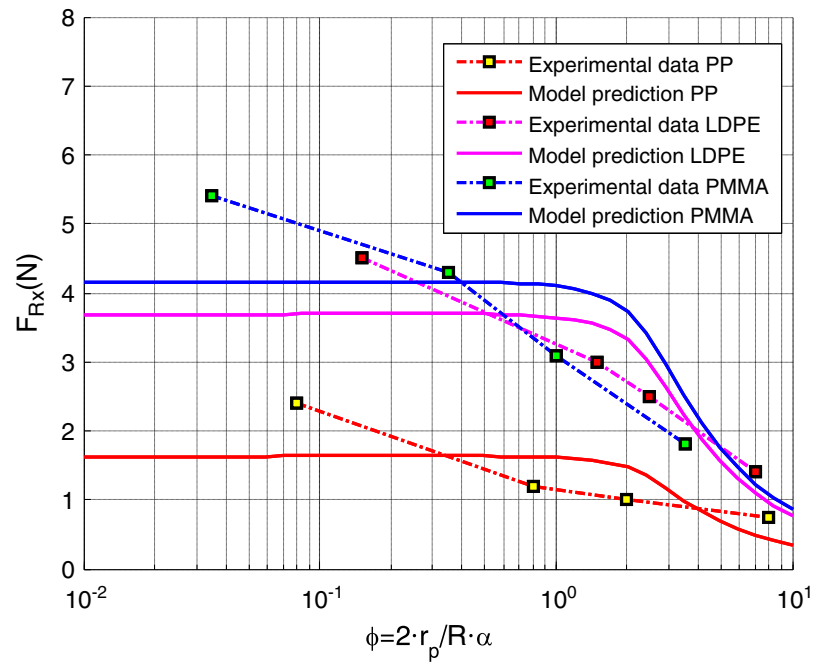

Fig. 13. Friction force $F_{R x}$ acting on the pin. Positive $\alpha$.

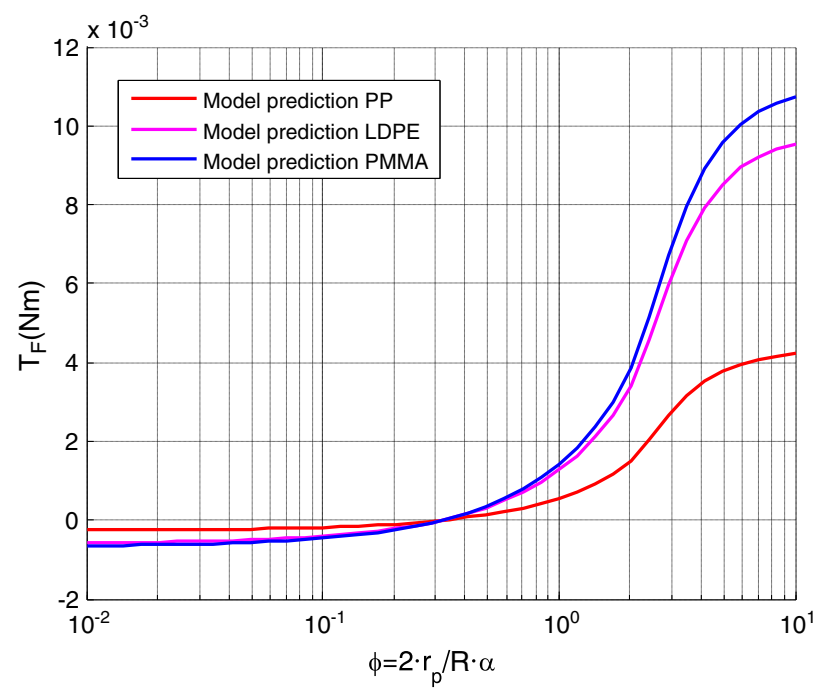

Fig. 14. Friction torque acting on the pin. Positive $\alpha$.

Table 2

Best values of $\mathrm{p}$ in least mean square sense (LMSE) for $\phi \epsilon[10]$.

\begin{tabular}{lll}
\hline Optimisation LMSE & PP & LDPE \\
\hline $\mathrm{p}$ & $2.5042 \cdot 10^{-3}$ & $9.0846 \cdot 10^{-3}$ \\
\hline
\end{tabular}

elastic depending on the contact pressure. A suitable criterion to classify the type of contact area consists on selecting an elastic asperity contact if the contact pressure is less than $0.6 \mathrm{H}, \mathrm{H}$ is the hardness and plastic asperity contact otherwise [9].

The PAC and torque predictions for this model are shown in Figs. 17, 18 for positive $\alpha$ values and Figs. 19,20 for negative $\alpha$ values respectively. The torque predictions have the same tendencies of the experimental data.

\section{Improved probabilistic model for pin-on-disc configuration}

If the pin behaves as an elastic deformable body, a simplified analysis of the stresses acting on the pin can be performed using the elementary elastic bending theory. The contact pressure along the pin is higher in the vicinities of the "leading" edge than in the "trailing" edge due to a slight bending produced by the friction force, Fig. 21. 


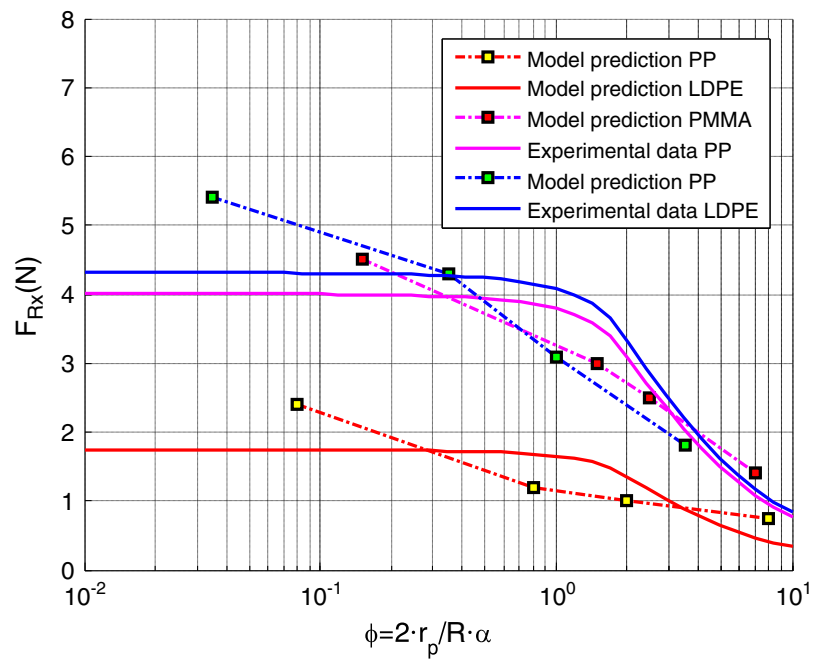

Fig. 15. Friction force $\mathrm{F}_{\mathrm{Rx}}$ acting on the pin. Negative $\alpha$.

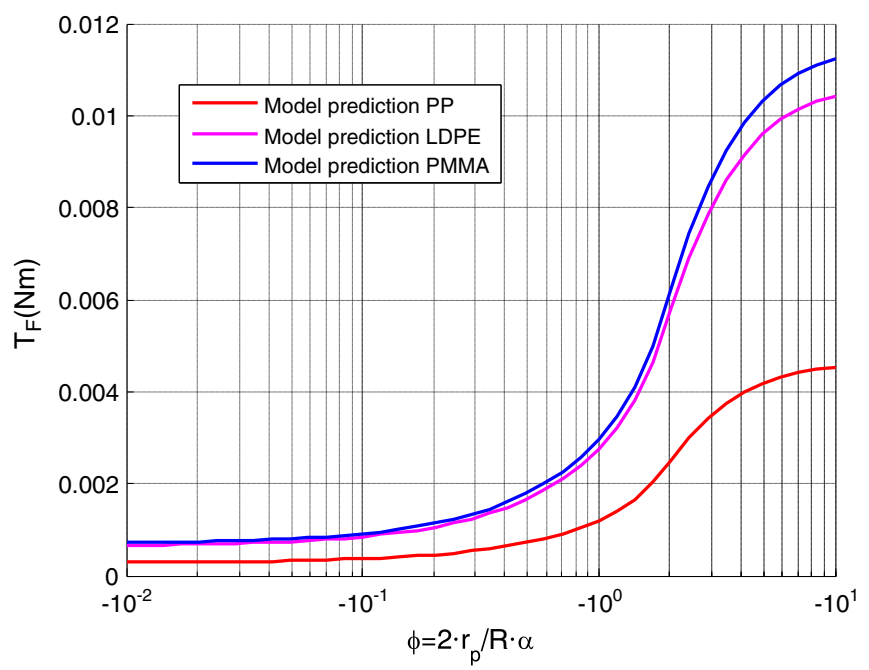

Fig. 16. Friction torque acting on the pin. Negative $\alpha$.

A non uniform distribution of contact stress leads to a non uniform distribution of probability of asperity contacts within the contact area. Therefore, this new distribution can produce a friction force in the direction of $y$-axis different to 0 . The contact pressure is obtained using the theory of elastic bending [10]. A bar under a bending couple has the stresses shown in Eq. (10).

$$
\sigma_{z}=\frac{E}{\mathrm{R}} \mathrm{x} \quad \sigma_{y}=\sigma_{x}=\tau_{x y}=\tau_{x z}=\tau_{y z}=0
$$

where $\mathrm{R}$ is the radius of curvature and $E$ is the Young's modulus. The value of $\sigma_{z}$ is a plane that contains the 'y' axis.

The moment created by the distribution of $\sigma_{z}$ is given by Eq. (11).

$$
M_{y}=\int \sigma_{z} \mathrm{xdA}
$$

Table 3

Best values of $\mathrm{p}$ in least mean square sense (LMSE) for $\phi \epsilon\left[-10,-10^{-2}\right]$.

\begin{tabular}{llll}
\hline Optimisation LMSE & PP & LDPE & PMMA \\
\hline $\mathrm{p}$ & $2.6813 \cdot 10^{-3}$ & $9.0881 \cdot 10^{-3}$ & $4.4164 \cdot 10^{-4}$ \\
\hline
\end{tabular}




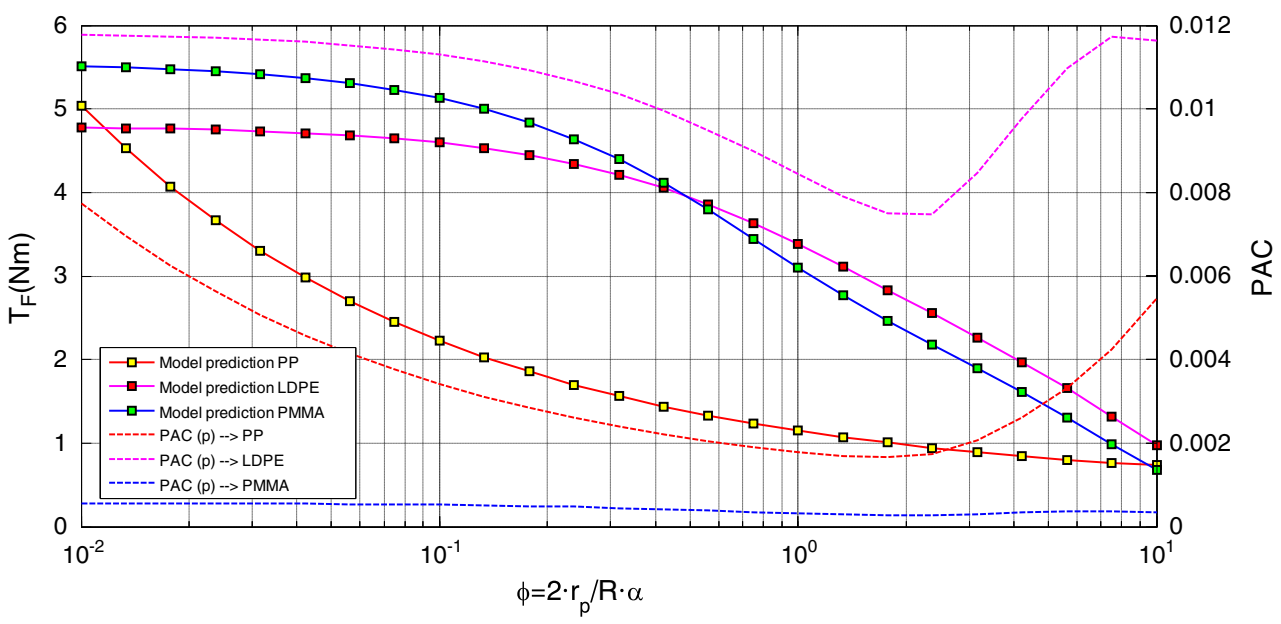

Fig. 17. Probability of asperity contact (PAC) is a function of $\alpha$. Obtained from the experimental x-component of the friction force acting on the pin. Positive $\alpha$ values.

The determination of ' $\mathrm{k}_{1}$ ' is shown in Eq. (12). Fig. 22 helps to visualise the equivalent force system.

$$
\begin{aligned}
& \sum M=0 \\
& +\mathrm{F}_{\mathrm{R}} \frac{\mathrm{h}}{2}=-\int \sigma_{z} \mathrm{xdA}=-\int \frac{\mathrm{k}_{1}}{\mathrm{r}_{\mathrm{p}}} \mathrm{x}^{2} \mathrm{dA}=-\frac{\mathrm{k}_{1}}{\mathrm{r}_{\mathrm{p}}} \int_{0}^{2 \pi} \int_{0}^{\mathrm{r}_{\mathrm{p}}}(\mathrm{r} \cos (\theta))^{2} r d r d \theta=-\frac{\mathrm{k}_{1}}{\mathrm{r}_{\mathrm{p}}} \frac{\pi}{4} \mathrm{r}_{\mathrm{p}}^{4}
\end{aligned}
$$

Although the contact pressure in contact theory is normally expressed as positive, in elasticity a compressive stress is expressed as negative. In this study the contact pressure is positive.

Using the Principle of Superposition it is possible to divide the stress distribution in two different problems: the compression and the bending, Fig. 21.

As a result, the contact pressure can be expressed as shown in Eq. (13):

$$
\sigma_{z}=k_{0}+k_{1} / r_{\mathrm{p}} \mathrm{x}
$$

and $\mathrm{k}_{0}, \mathrm{k}_{1}$ expressions are shown in Eq. (14).

$$
\mathrm{k}_{0}=\frac{\mathrm{L}}{\pi \mathrm{r}_{\mathrm{p}}^{2}} \quad \mathrm{k}_{1}=\frac{-2 \mathrm{~F}_{\mathrm{R}} \mathrm{h}}{\pi \mathrm{r}_{\mathrm{p}}^{3}}
$$

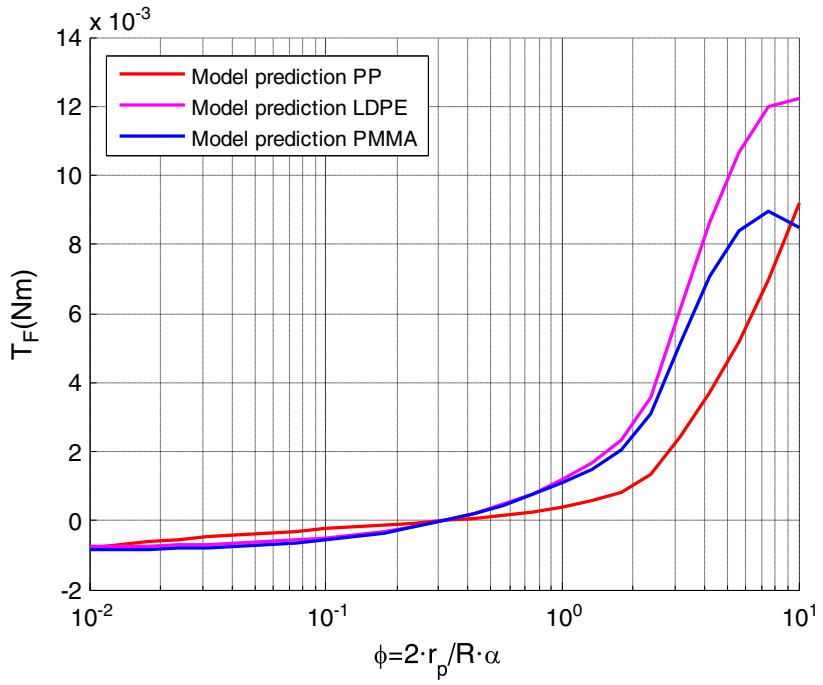

Fig. 18. Friction torque predictions if the PAC varies with $\alpha$. Positive $\alpha$ values. 


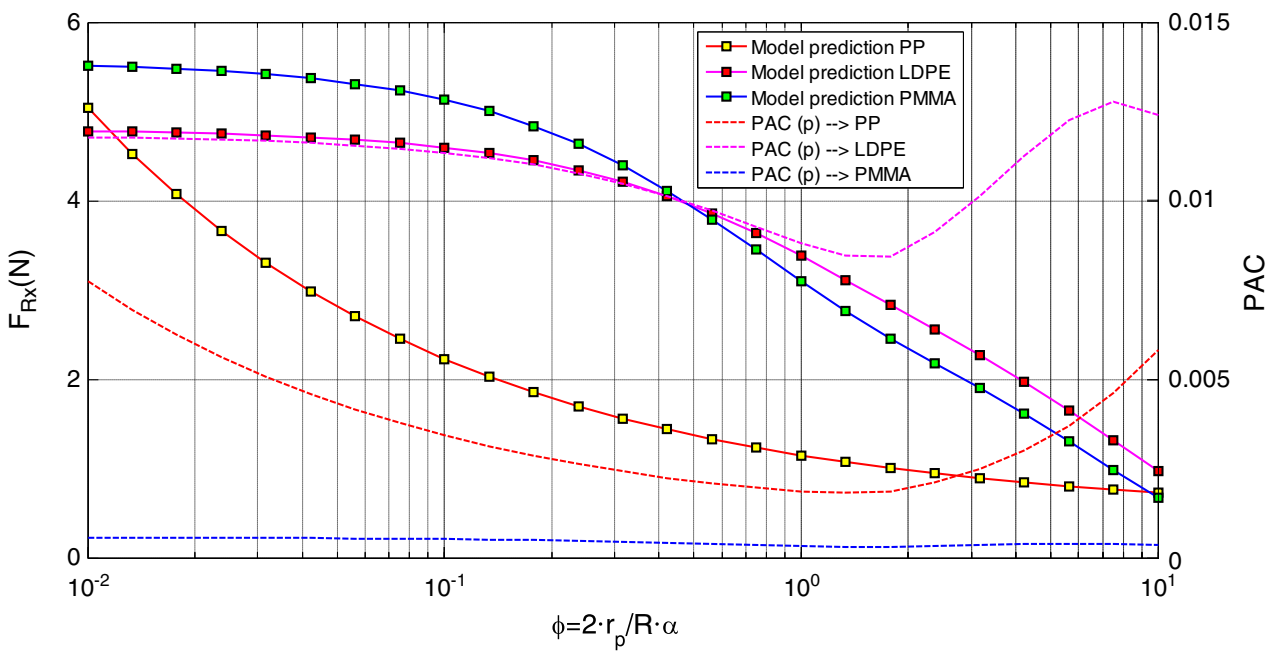

Fig. 19. Probability of asperity contact (PAC) is a function of $\alpha$. Obtained from the experimental x-component of the friction force acting on the pin. Negative $\alpha$ values.

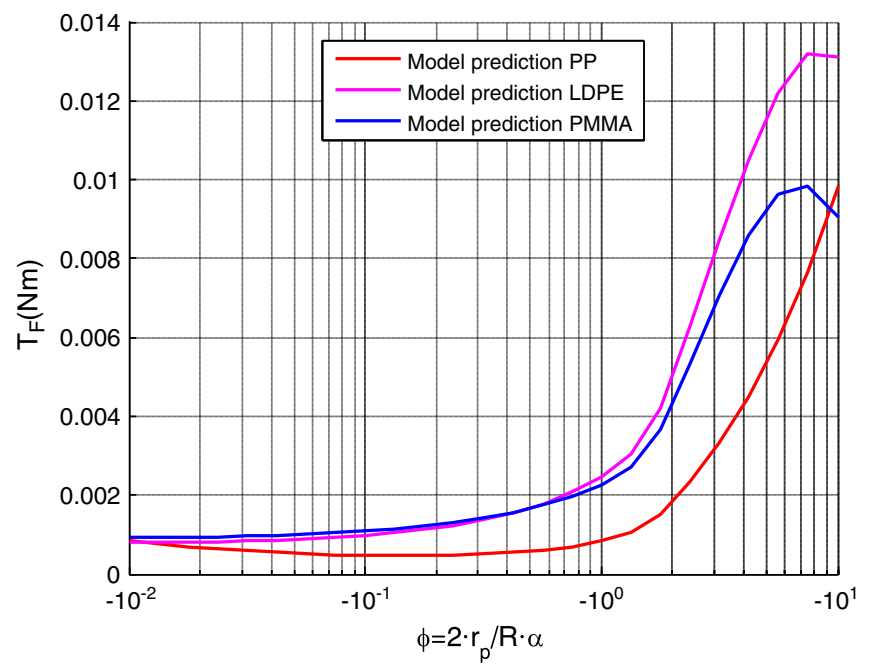

Fig. 20. Friction torque predictions if the PAC varies with $\alpha$. Negative $\alpha$ values.

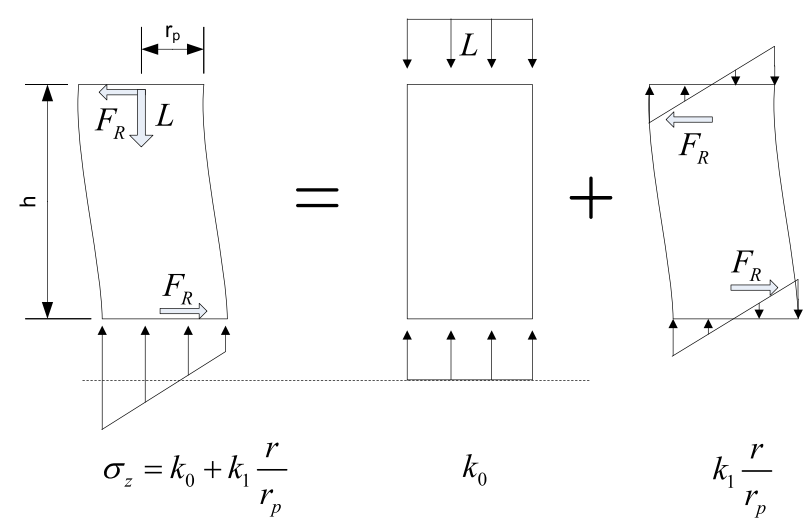

Fig. 21. Elastic model of the pin to obtain contact pressure. Principle of Superposition. L is the applied load. 


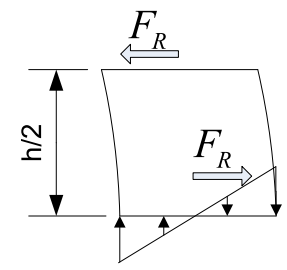

Fig. 22. Equivalent force system for the determination of $k_{1}$.

where $\mathrm{L}$ is the load, $\mathrm{h}$ is the height of the pin and $\mathrm{F}_{\mathrm{R}}$ is the resultant friction force.

It is possible to calculate a limit of height or a limit of friction force to ensure the whole pin surface is making contact with the disc. This limitation is expressed in Eq. (15).

$$
0 \leq \mathrm{k}_{0}+\frac{\mathrm{k}_{1}}{\mathrm{r}_{\mathrm{p}}} \mathrm{x}
$$

The condition of contacting surfaces separation occurs in the point where $x$ is equal to the pin radius $\left(r_{p}\right)$, Eq. (16).

$$
\mathrm{k}_{0} \geq \mathrm{k}_{1} \rightarrow \frac{\mathrm{L}}{\pi \mathrm{r}_{\mathrm{p}}^{2}} \geq \frac{2 \mathrm{~F}_{\mathrm{R}} \mathrm{h}}{\pi \mathrm{r}_{\mathrm{p}}^{3}} \rightarrow \frac{\mathrm{Lr}_{\mathrm{p}}}{2} \geq \mathrm{F}_{\mathrm{R}} \mathrm{h}
$$

This limitation implies a pin can be separated from the disc if its height or the friction force is high enough.

The stress distribution on the counterface of the pin can be generalised for a resultant friction force that it is not parallel to the $\mathrm{x}$-axis. $\theta_{R}$ is the angle between the $\mathrm{x}$-axis and the resultant of the experimental friction force, hence the contact stress distribution is:

$$
\sigma_{z}=\mathrm{k}_{0}+\mathrm{k}_{1} / \mathrm{r}_{\mathrm{p}} \cos \left(\theta-\theta_{\mathrm{R}}\right) \cdot \mathrm{r}
$$

The friction forces and friction pin torque for this new model can be expressed as shown in Eq. (18):

$$
\begin{aligned}
\mathrm{F}_{\mathrm{R}_{\mathrm{x}}}= & -\int_{0}^{\mathrm{r}_{\mathrm{p}}} \int_{0}^{2 \pi} \mathrm{PAC} \cdot \tau \frac{[\mathrm{R}+(1-\alpha) \mathrm{r} \sin (\theta)] \mathrm{r}}{\sqrt{\left[\mathrm{R}^{2}+2 \mathrm{Rr}(1-\alpha) \sin (\theta)+(1-\alpha)^{2} \mathrm{r}^{2}\right]}} d r d \theta \\
\mathrm{F}_{\mathrm{R}_{\mathrm{y}}}= & -\int_{0}^{\mathrm{r}_{\mathrm{p}} 2 \pi} \int_{0}^{2 \pi} \mathrm{PAC} \cdot \tau \frac{(\alpha-1) \mathrm{r}^{2} \cos (\theta)}{\sqrt{\left[\mathrm{R}^{2}+2 \mathrm{Rr}(1-\alpha) \sin (\theta)+(1-\alpha)^{2} \mathrm{r}^{2}\right]}} d r d \theta \\
\mathrm{T}_{\mathrm{F}}= & \int_{0}^{\mathrm{r}_{\mathrm{p}}} \int_{0}^{2 \pi} P A C \cdot \tau \frac{[\mathrm{R}+(1-\alpha) \mathrm{r} \sin (\theta)] \mathrm{r}^{2} \sin (\theta)}{\sqrt{\left[\mathrm{R}^{2}+2 \mathrm{Rr}(1-\alpha) \sin (\theta)+(1-\alpha)^{2} \mathrm{r}^{2}\right]}} d r d \theta \ldots \\
& -\int_{0}^{\mathrm{r}_{\mathrm{p}} 2 \pi} \int_{0}^{2 \pi} \mathrm{PAC} \cdot \tau \frac{(\alpha-1) \mathrm{r}^{3} \cos ^{2}(\theta)}{\sqrt{\left[\mathrm{R}^{2}+2 \mathrm{Rr}(1-\alpha) \sin (\theta)+(1-\alpha)^{2} \mathrm{r}^{2}\right]}} d r d \theta \\
\theta_{\mathrm{R}}= & \operatorname{arctg}\left(\frac{\mathrm{F}_{\mathrm{y}}}{\mathrm{F}_{\mathrm{x}}}\right)
\end{aligned}
$$

The probability of asperity contact for this model is shown in Eq. (19).

$$
P A C \equiv\left\{\begin{array}{c}
p\left(k_{0}+\frac{k_{1}}{r_{p} r} \cos \left(\theta-\theta_{R}\right)\right) \\
0 \quad \text { if }\left(k_{0}+\frac{k_{1}}{r_{p}} r \cos \left(\theta-\theta_{R}\right)\right) \leq 0 \\
r \in\left(0, r_{p}\right) \theta \in(0,2 \pi)
\end{array}\right.
$$

The main improvements of this model in respect to the previous one are the predictions of:

- The "y" component of the friction force.

- The contact stress distribution within the pin. 


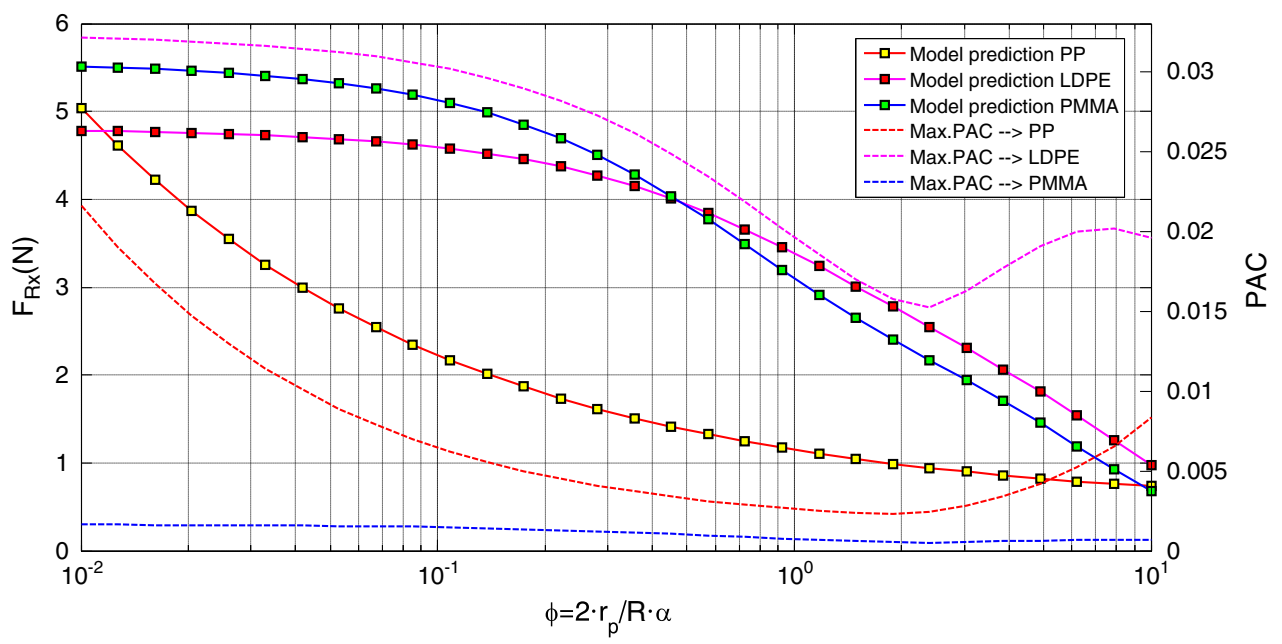

Fig. 23. Maximum value of the probability of asperity contact (PAC) is a function of $\alpha$. Obtained from the experimental x-component of the friction force acting on the pin. Positive $\alpha$ values.

- The probability of asperity contact.

- The real contact area due to elastic and plastic asperity contacts according to the mentioned criteria of $0.6 \mathrm{H}$.

\section{Possible applications of the improved model}

Several studies of adhesive wear in dry and lubricated contacts are reported in the literature [7,8]. The probabilistic models are based on Archard Wear Law. Amongst them, the most complete in the literature predicts adhesive wear for lubricated contacts [7] and it is shown in Eq. (20).

$$
V=\sqrt{\left(1+3 \mu^{2}\right)} \beta L\left(k_{e} A_{e}+k_{p} A_{p}\right)
$$

Where

the predicted volume of adhesive wear.

the coefficient of friction. the fractional film defect. the sliding distance.

$k_{\mathrm{e}} \quad$ is the wear coefficient for non welded junctions

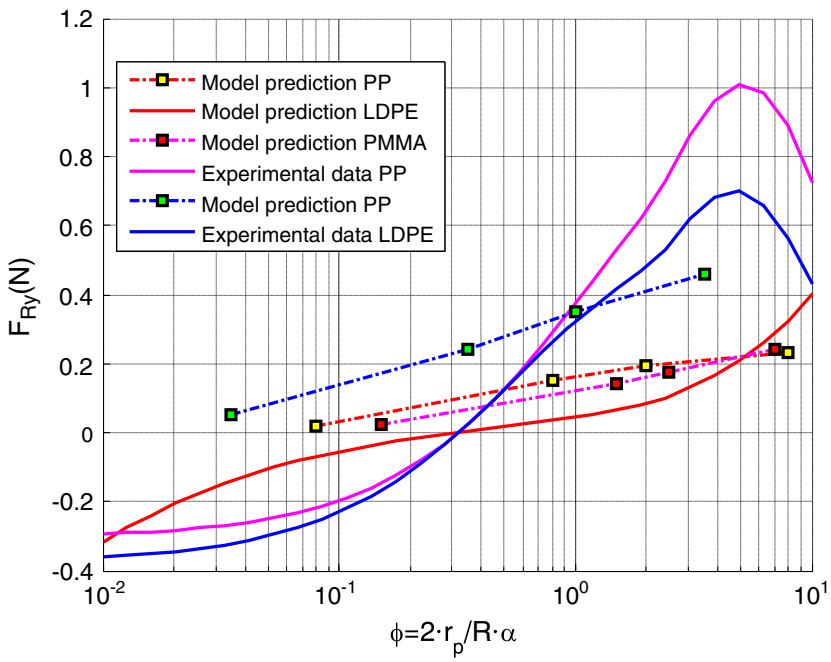

Fig. 24. Predictions of the y-component of the frictional force. Positive $\alpha$ values. 


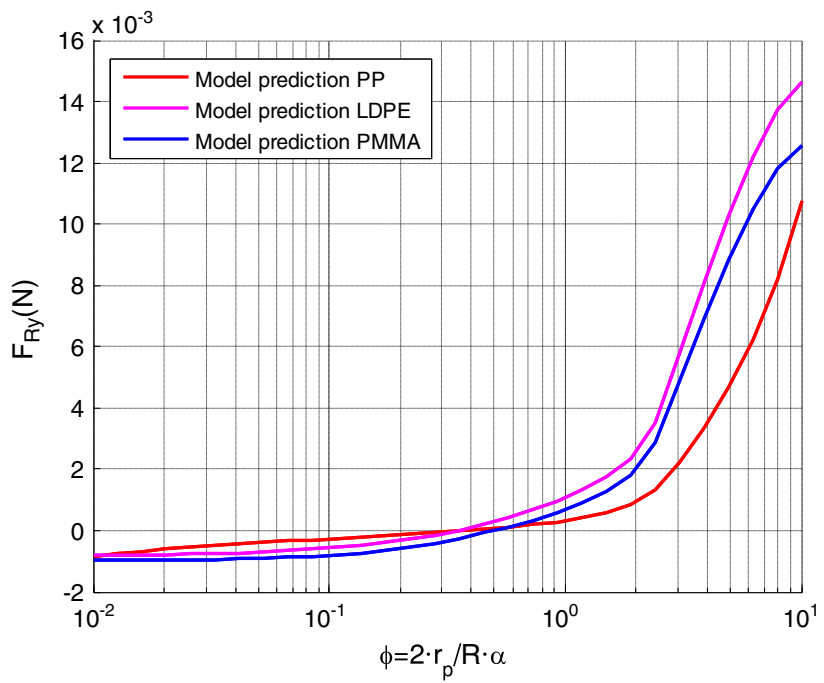

Fig. 25. Friction torque predictions of the proposed model. Positive $\alpha$ values.

$\mathrm{k}_{\mathrm{p}} \quad$ is the wear coefficient for welded junctions

$\mathrm{A}_{\mathrm{e}} \quad$ the area of contact for elastic asperity contacts.

$A_{p} \quad$ the area of contact for plastic asperity contacts.

Another application of the proposed model is the study of the electrical contact resistance (ECR). This is of special interest for the assessment of the boundary layer formation under mixed and boundary lubrication regimes. The study can be carried out assuming only the plastic asperity contacts are the main contributors for the final conductance [9] as shown in Eq. (21).

$$
G_{p}=\frac{A_{p}}{\rho}
$$

Where

$\rho$

the electrical resistivity of the material.

\section{Validation of the preliminary model with experimental data}

The model predictions for a pin diameter of $8 \mathrm{~mm}$, a pin height of $10 \mathrm{~mm}$, a load of $10 \mathrm{~N}$, a distance from the centre of the pin to the centre of the disc of $25 \mathrm{~mm}$ and positive $\alpha$ values are shown in Figs. 23-25. Results for same input parameters and negative $\alpha$

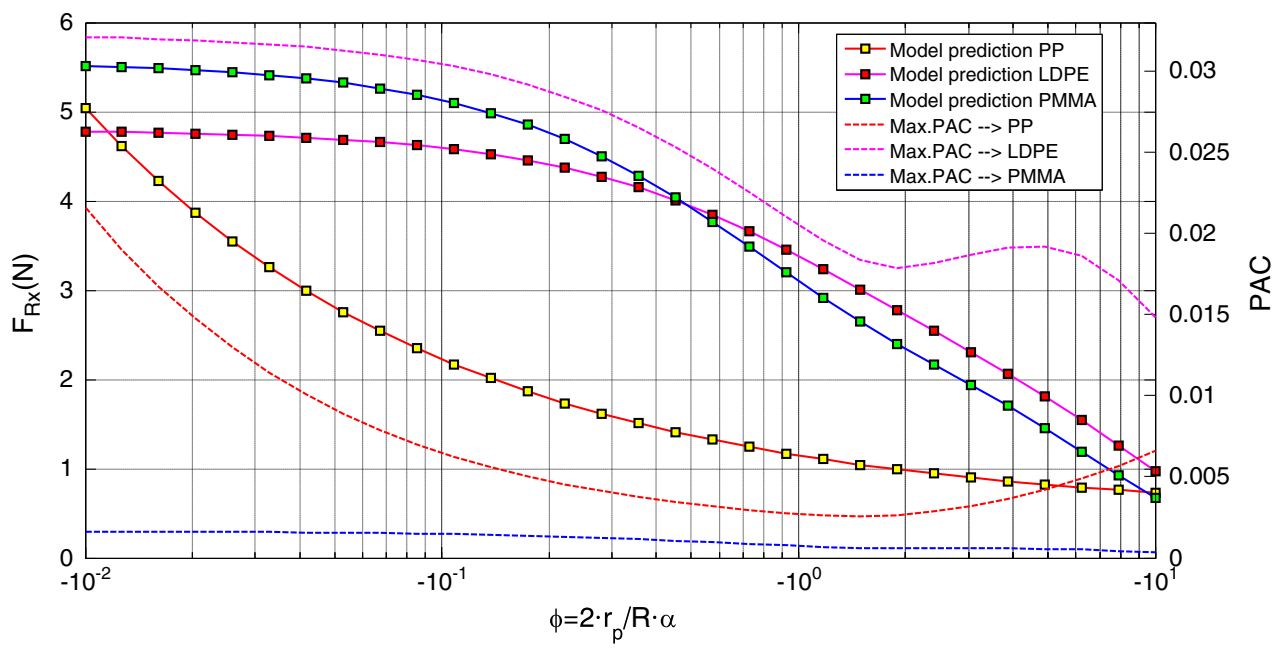

Fig. 26. Maximum value of the probability of asperity contact (PAC) is a function of $\alpha$. Obtained from the experimental x-component of the friction force acting on the pin. Negative $\alpha$ values. 


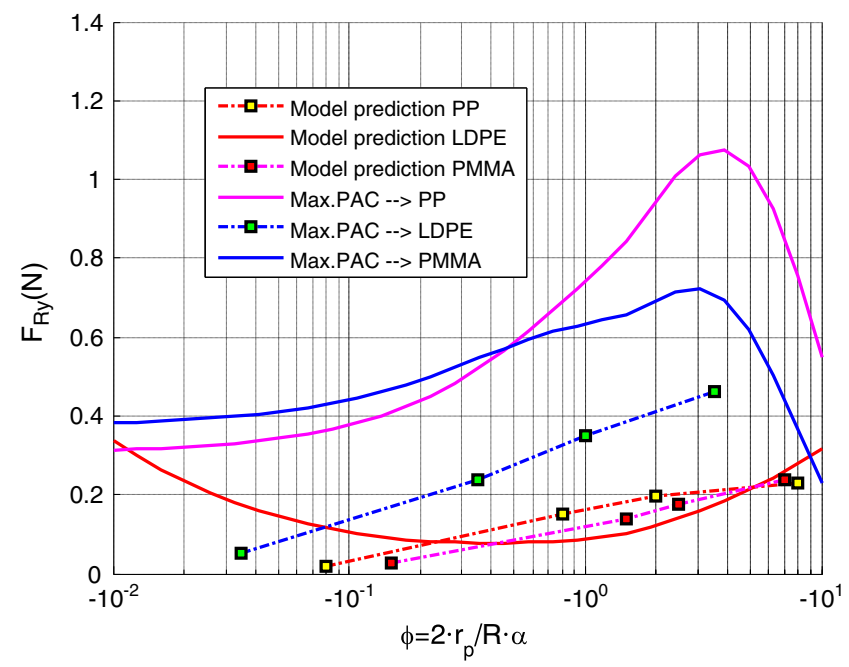

Fig. 27. Predictions of the $y$-component of the frictional force. Negative $\alpha$ values.

values are shown in Figs. 26-28. The model predicts a y-component different than 0 but there is certain disagreement with the experimental data.

The PAC values within the pin are shown in Fig. 29 for Polypropylene (PP) and positive $\alpha$ values.

The proposed model results are in better agreement with the experimental data than the predictions of the previous models. The combination of a variable PAC within the area of contact for different experimental conditions $\left(\omega_{d}, \omega_{p}, r_{p}, R, h, \Theta_{R}\right)$ makes this model a useful tool for the evaluation of adhesive wear models.

\section{Conclusions}

A new model has been developed using the kinematics of the pin-on-disc apparatus, the use of the probabilistic approach for wear prediction and elastic bending theory which improves the previous study [4]. This new model predicts the different components of the resultant force acting on the pin, the pin torque, the stress distribution along the contact area, the probability of asperity contact and the real area of contact distinguishing between elastic and plastic area of contact. The proposed model is of interest in electrical contact resistance (ECR) studies because it can predict the conductance using the predicted real contact area due to plastic asperity contacts.

This model will be used in future work to assess the asperity contact theory and adhesion models since it predicts the pressure distribution and the plastic and elastic real area distribution within the contact.

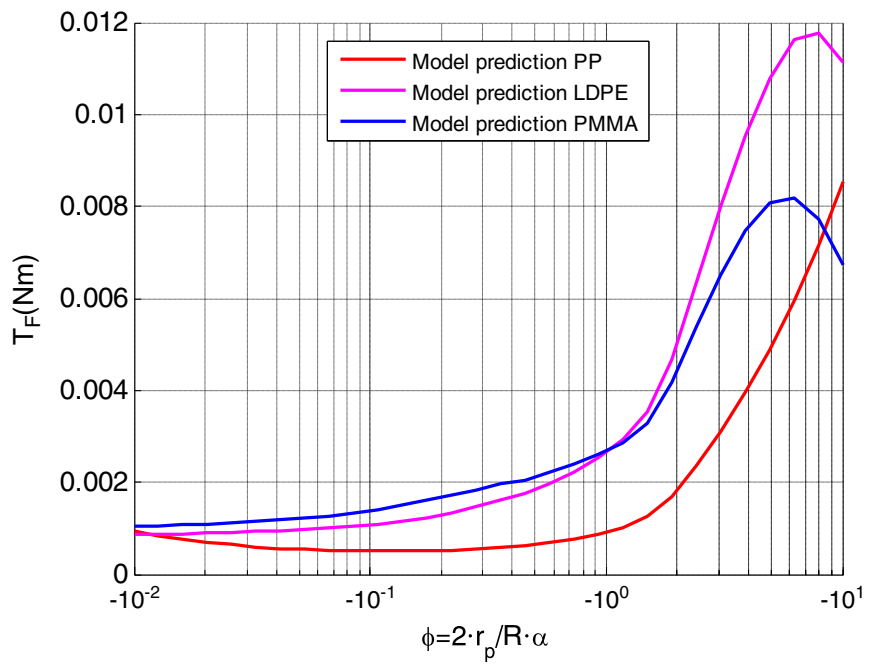

Fig. 28. Friction torque predictions of the proposed model. Negative $\alpha$ values. 

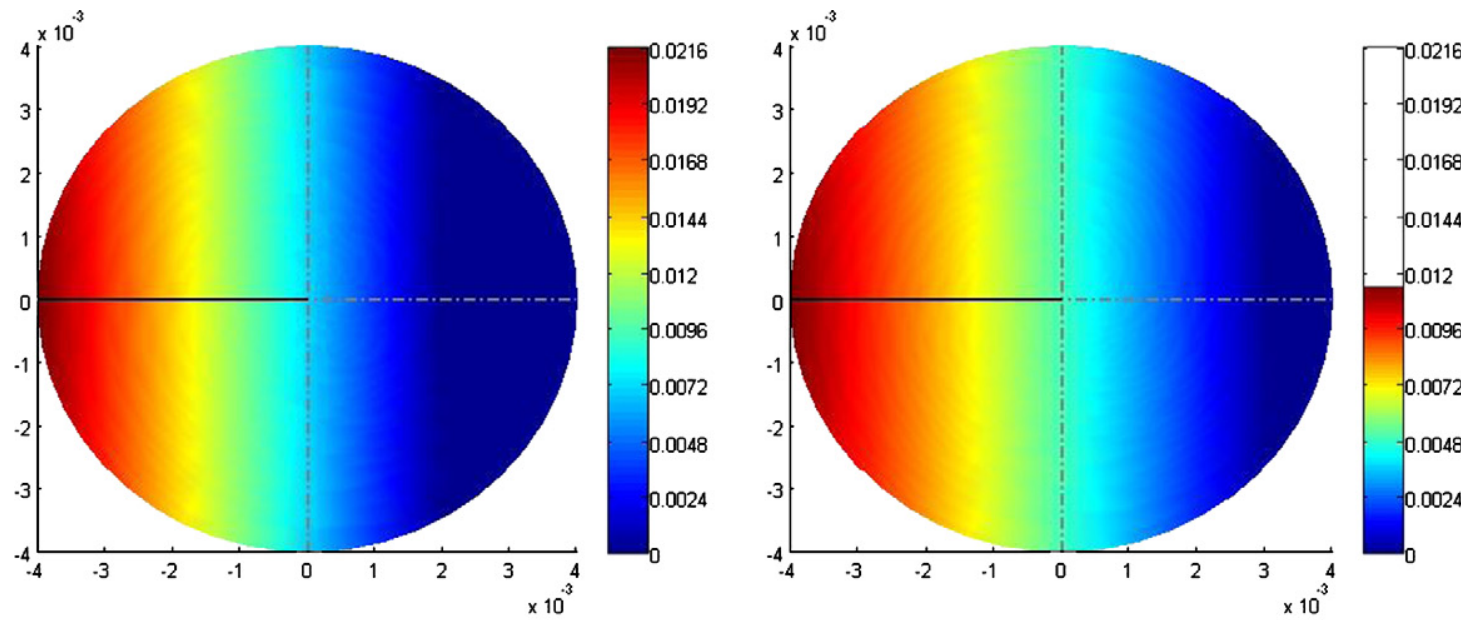

$\theta_{\mathrm{R}}=180.00^{\circ}, \alpha=3.125 \cdot 10^{-2}, \phi=0.010$

$\theta_{\mathrm{R}}=180.12^{\circ}, \alpha=1.028 \cdot 10^{-1}, \phi=0.033$
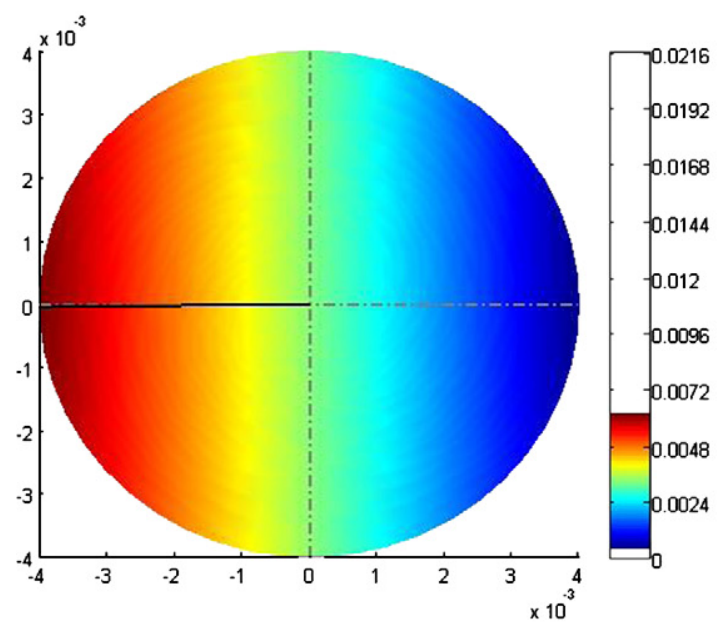

$\theta_{\mathrm{R}}=180.70^{\circ}, \alpha=3.383 \cdot 10^{-1}, \phi=0.108$
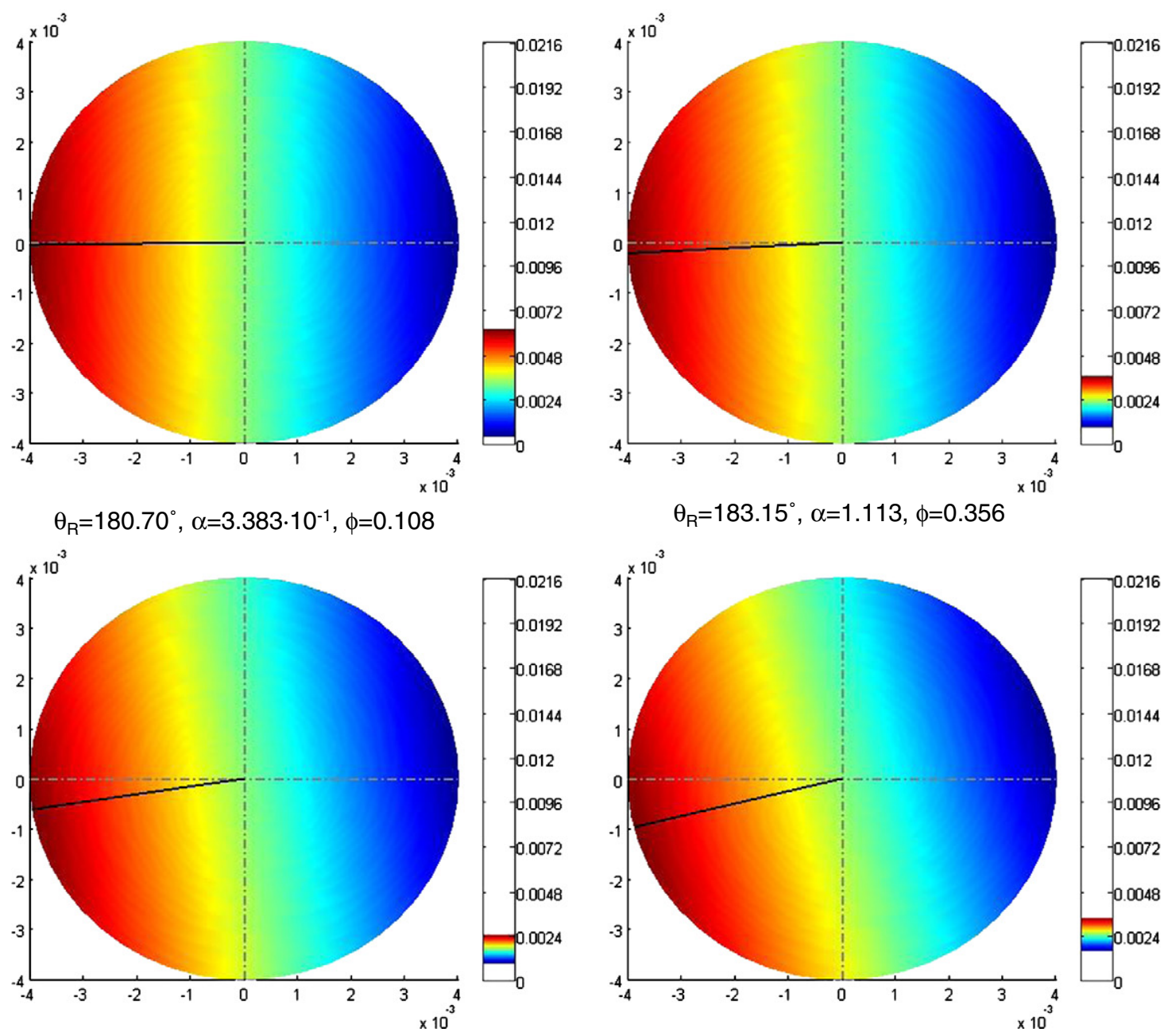

$\theta_{R}=188.80^{\circ}, \alpha=3.663, \phi=1.172$

$\theta_{\mathrm{R}}=183.15^{\circ}, \alpha=1.113, \phi=0.356$

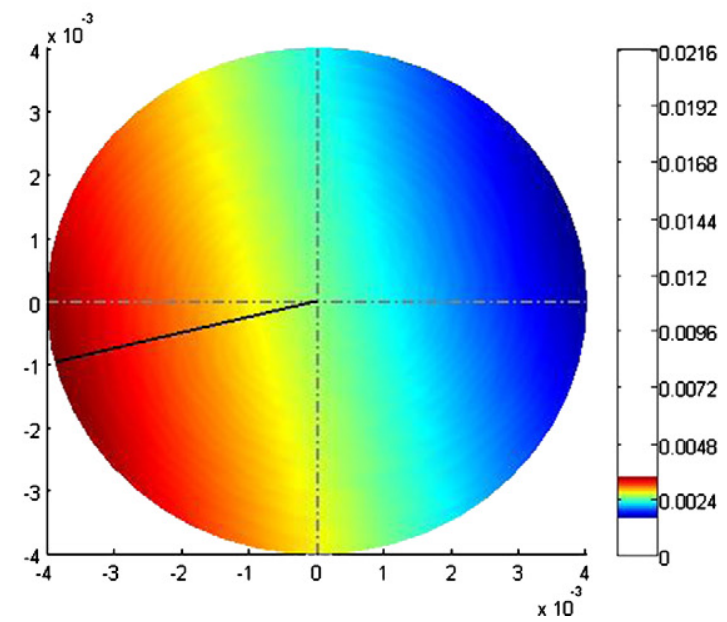

$\theta_{R}=193.94^{\circ}, \alpha=12.052, \phi=3.857$

Fig. 29. PAC predictions for PP for different $\phi$. Positive $\alpha$ values. 


\section{List of symbols}

$\tau \quad$ Interfacial shear stress

$\mathrm{V} \quad$ Linear velocity of the pin in the pin on plate model

$\mathrm{O}_{\mathrm{p}} \quad$ Centre of the pin

$\omega_{\mathrm{p}} \quad$ Angular velocity of the pin

$\vec{u}, \vec{s} \quad$ Velocity vectors

$\omega_{\mathrm{d}} \quad$ Angular velocity of the disc

$\mathrm{O}_{\mathrm{d}} \quad$ Centre of the disc

$\mathrm{R} \quad$ Distance from the centre of the pin $\mathrm{O}_{\mathrm{p}}$ to the centre of the disc $\mathrm{O}_{\mathrm{d}}$

$r \quad$ Distance of a point $P$ on the pin from its centre $\mathrm{O}_{p}$

$r_{p} \quad$ Pin radius

A Contact Area

dA Differential of the contact area

$\mathrm{A}_{\mathrm{r}} \quad$ Real Area of Contact

$\mathrm{p} \quad$ Simplest definition of the probability of contact, ratio between $\mathrm{A}_{\mathrm{r}}$ and $\mathrm{A}$

$\alpha \quad$ Ratio between $\omega_{\mathrm{p}}$ and $\omega_{\mathrm{d}}$

$\Psi \quad$ Angle of the resultant force acting on the pin

$F_{R} \quad$ Resultant friction force acting on the pin

$\mathrm{dF}_{\mathrm{R}} \quad$ Differential friction force

$\mathrm{T}_{\mathrm{F}} \quad$ Friction torque

$\mathrm{dT}_{\mathrm{F}} \quad$ Differential friction torque

$\phi \quad$ Dimensionless number defined as $2 \cdot r_{\mathrm{p}} / \mathrm{R} \cdot \alpha$

PAC Probability of Asperity Contact

$\mathrm{H} \quad$ Hardness

$\sigma \quad$ Stress

M Moment created by the distribution of $\sigma$

$\mathrm{k}_{0}, \mathrm{k}_{1} \quad$ Constant of the proposed model

L Applied load

h Pin height

$\mathrm{F}_{\mathrm{R}} \quad$ Resultant friction force

V Predicted volume of adhesive wear

$\mu \quad$ Coefficient of friction

$\beta \quad$ Fractional film defect

L Sliding distance

$\mathrm{k}_{\mathrm{e}} \quad$ The wear coefficient for non welded junctions

$\mathrm{k}_{\mathrm{p}} \quad$ The wear coefficient for welded junctions

$\mathrm{A}_{\mathrm{e}} \quad$ The area of contact for elastic asperity contacts

$A_{p} \quad$ The area of contact for plastic asperity contacts

$\mathrm{G}_{\mathrm{p}} \quad$ Conductance assuming plastic asperity contacts

$\rho \quad$ Electric resistivity of the material

\section{Acknowledgements}

The authors wish to thank the Engineering and Physical Sciences Research Council (EPSRC) and the Royal National Lifeboat Institution (RNLI) for funding this work.

\section{References}

[1] B. Bhushan, “Modern Tribology Handbook”, CRC Press. ISBN: (2000) 0-8493-8403-6.

[2] B.J. Briscoe, T.A. Stolarski, Wear of polymers in the pin-on-disk configuration, American Chemical Society (1985) 303-313.

[3] B.J. Briscoe, T.A. Stolarski, Transfer wear of polymers during combined linear motion and load axis spin, Wear (1985) $121-137$.

[4] T.A. Stolarski, Friction in a pin-on-disc configuration, Mechanism and Machine Theory 24 (1989) $373-381$.

[5] Z. Lisowski, T.A. Stolarski, A modified theory of adhesive wear in lubricated contacts, Wear (1981) 333-345.

[6] J.F. Archard, Contact and rubbing of flat surfaces, Journal of Applied Physics 24 (8) (1953) 981-988.

[7] T.A. Stolarski, Adhesive wear of lubricated contacts, Tribology International (1979) 169-179.

[8] T.A. Stolarski, A system for wear prediction in lubricated sliding contacts, Lubrication Science 8-4 (1996) 315-351.

[9] J.A. Greenwood, J.B.P. Williamson, Contact of nominally flat surfaces, Proceedings of the Royal Society of London A 295 (1966) 300-319, doi:10.1098/ rspa.1966.0242.

[10] S.P. Timoshenko, J.N. Goodier, “Theory of elasticity”, McGraw Hill. ISBN: (1970) 0070858055.

[11] R.G. Bayer, "Mechanical wear fundamentals and testing", Marcel Dekker. ISBN: (2004) 0824746201. 